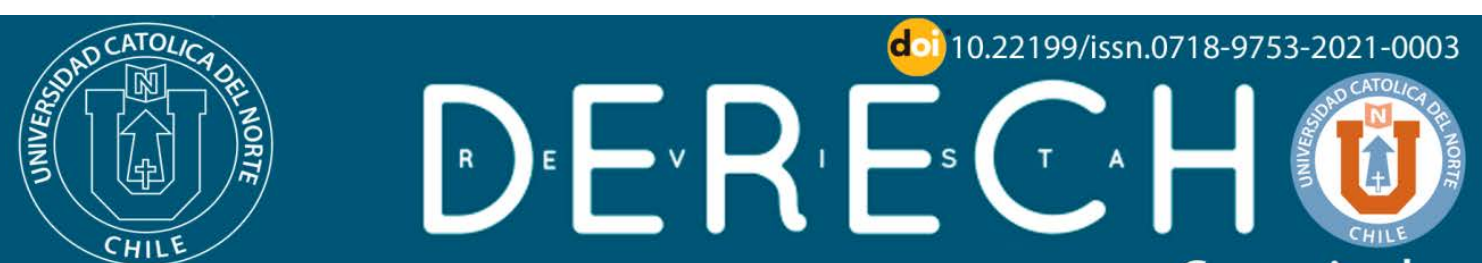

REVISTAS CIENTIIFICAS
de la Universidad Catolica del Norte.

C o qu i m bo

ISSN: 0718-9753 (En línea)

\title{
La consulta de la sanción ambiental: un trámite procesal innecesario.
}

\section{The ex officio court review of the environmental sanction: an unneces-} sary procedural requirement.

\section{Dominique Hervé Espejo' (D) https://orcid.org/0000-0002-4006-4872 \\ Macarena Vargas Pavez ${ }^{2}$ (D) https://orcid.org/0000-0003-4130-5276 \\ 'Universidad Diego Portales, Santiago, Chile. Profesora de Derecho Ambiental. Abogada. Doctora en Derecho, Pontificia U. Católica de Valparaíso. dominique.herve@udp.cl ${ }^{2}$ Universidad Diego Portales, Santiago, Chile. Profesora de Derecho Procesal. Abogada. Doc- tora en Derecho, Pontificia U. Católica de Valparaíso. macarena.vargas@udp.cl}

\section{Resumen:}

La consulta como trámite procesal no suele generar mayor controversia, pues en la actualidad su aplicación se encuentra limitada a una muy baja proporción de procedimientos en el marco de nuestro ordenamiento jurídico. Sin embargo, a partir de la dictación de la Ley No 20.600 (2012) -donde se establece la obligación de elevar en consulta ciertas sanciones impuestas por la Superintendencia del Medio Ambiente- la finalidad, alcances y límites de esta institución procesal ha vuelto a ser parte del debate. Más allá de un recuento de su aplicación por los tribunales ambientales y los problemas que se han detectado en estos años de vigencia, el objetivo de este trabajo es analizar si esta institución se justifica desde la perspectiva del interés público involucrado en la aplicación de sanciones ambientales, concluyendo que se trata de un trámite innecesario.

Palabras Clave: Derecho ambiental; Tribunales ambientales; Responsabilidad de daños ambientales.

\section{Abstract:}

The ex officio court review (consulta) as a procedural requirement does not usually generate controversy, since at present its application is limited to a very low proportion of procedures within our legal system. However, since the enactment of Law No20.600 (2012) - where the obligation to raise certain sanctions applied by the Superintendence of the Environment for juditial review, is established - the purpose, scope and limits of this procedural institution has become a part of the legal debate. Beyond a recount of its application by the environmental courts and the problems that have been detected in these years, the objective of this work is to analyze whether this institution is justified from the perspective of the public interest involved in the application of environmental sanctions, concluding that it is an unnecessary procedure.

Keywords: Environmental law; Environmental courts; Liability for environmental damages 


\section{Introducción}

Con la creación de los Tribunales Ambientales en el año 2012, se vuelve a incorporar en nuestro ordenamiento jurídico una institución de escasa presencia en la legislación nacional: el trámite procesal de la consulta. En esta nueva versión, sin embargo, la consulta de la sanción ambiental adopta características propias, ya que se trata de la revisión y control previo de una decisión sancionatoria administrativa por parte de un órgano judicial. Estas características, sumadas a las que ya presentaba la consulta en su versión tradicional permiten, en estos casi siete años de aplicación, identificar algunos problemas y algunos elementos que vale la pena analizar.

El presente trabajo, tiene por objeto analizar la institución procesal de la consulta (1) y su evolución en el ordenamiento jurídico nacional (2). A continuación, se procede a revisar el origen, contenido y aplicación de la obligación de someter a consulta, ciertas sanciones ambientales, como trámite procesal ante los tribunales ambientales (3), para luego proceder a la identificación y análisis de los principales aspectos y problemas que se han manifestado y discutido en torno a la aplicación de esta institución, incluyendo su justificación como un asunto de interés público (4). Se finaliza con algunas conclusiones.

\section{El trámite de la consulta}

El análisis de la consulta como trámite procesal se enmarca dentro del estudio de los recursos procesales, particularmente del examen del recurso de apelación en tanto medio de impugnación.

El recurso de apelación encuentra su fundamento en el principio de la doble instancia, en virtud del cual el conocimiento y resolución de un asunto puede ser realizado en dos oportunidades y por dos tribunales distintos (Mosquera Ruíz y Maturana Miquel, 2010, p. 123). Ello supone que un tribunal superior jerárquico revisará lo resuelto por un tribunal inferior, pudiendo confirmar, revocar o sustituir (total o parcialmente) la resolución dictada por éste (Palomo Vélez, 2010).

Esta función revisora del recurso de apelación busca evitar la existencia de errores en las resoluciones judiciales, para lo cual la ley permite a la parte afectada denunciar esos defectos, buscando que el tribunal correspondiente reconsidere su postura (Couture Etcheverry, 2016, p. 218). Estos errores, pueden darse en la interpretación y aplicación de la ley procesal (errores in procedendo) o bien, en la interpretación y aplicación de la ley sustantiva (error in iudicatio) (Couture Etcheverry, 2016, pp. 281 y 282). 
Nuestro Código de Procedimiento Civil (Ley N 1.552, 1902) recoge de manera expresa la noción de la doble instancia, al señalar que el recurso de apelación tiene por objeto obtener que un tribunal superior jerárquico enmiende, conforme a derecho, una resolución dictada por un tribunal inferior (Ley $N^{\circ} 1.552,1902$, art. 186). La causal que las partes pueden esgrimir para solicitar esta revisión es el gravamen o agravio, esto es, no haber obtenido lo que se pretendía con ocasión del proceso (Mosquera Ruíz y Maturana Miquel, 2010, p. 138). Cuando ello ocurre, las partes o los terceros, que se ven perjudicados por una resolución judicial, se encuentran habilitados para ejercer un medio de impugnación, en este caso, un recurso de apelación (Orellana Torres, 2006).

En materia civil, nuestra legislación no define la expresión agravio, pero la doctrina y la jurisprudencia la ha entendido como la diferencia entre lo pedido y lo obtenido por la parte afectada (Bordalí Salamanca et al., 2016, p. 85). Ello surge a partir de la interpretación de normas del artículo 751 inciso primero del Código de Procedimiento Civil (1902), que regula la figura de la consulta en el procedimiento de hacienda. Allí se establece, como se verá más adelante, que toda sentencia definitiva que no sea apelada por las partes se elevará en consulta, siempre que sea desfavorable al interés fiscal. Esto último ocurre, de acuerdo a la norma antes citada, cuando no se acoge totalmente la demanda del Fisco, o su reconvención, o cuando no deseche en todas sus partes la demanda deducida contra el Fisco o la reconvención promovida por el demandado.

\subsection{Concepto de consulta}

Antes de definir qué debemos entender por consulta, es importante señalar que la interposición del recurso de apelación constituye una facultad para los litigantes (Mosquera Ruíz y Maturana Miquel, 2010, p. 128). Incluso más, la ley permite a las partes renunciar a los recursos procesales, de acuerdo a las facultades extraordinarias del mandato judicial (Ley № 1.552, 1902, art. 7, inc. 2). Lo harán expresamente, cuando -antes o después de notificada la resolución impugnable- manifiesten de manera inequívoca su voluntad en este sentido. Lo harán tácitamente, cuando los litigantes no interponen el referido recurso en la oportunidad procesal que la ley otorga para ello.

Por tanto, las partes podrán ejercer o no tal facultad en la medida que consideren que una determinada resolución les causa agravio, cuestión que deberán fundamentar en el respectivo recurso procesal tanto de una perspectiva objetiva como subjetiva (Mosquera Ruíz y Maturana Miquel, 2010, p. 127).

Es en este contexto en que la figura de la consulta cobra relevancia. ¿Qué sucede si la parte agraviada con una sentencia definitiva de primera instancia decide por las razones que estime pertinentes- no apelar? ¿Puede de oficio el tribunal supe- 
rior jerárquico revisar dicha sentencia y eventualmente modificarla o revocarla si así lo estima conveniente?

De acuerdo a lo antes señalado, si las partes -ejerciendo la facultad que la ley les ha conferido- deciden no apelar de una resolución judicial, el tribunal superior no podría conocer del fallo dictado en primera instancia. Sin embargo, la figura de la consulta surge como una excepción a esta regla, en tanto por mandato legal el superior jerárquico debe realizar una revisión de oficio de lo resuelto por el inferior. Siguiendo esta línea, Chaigneau del Campo (2000, p. 242) define a la consulta como aquel trámite procesal que busca que ciertas resoluciones judiciales -previamente establecidas por la ley- sean revisadas por las cortes de apelaciones cuando las partes no hayan ejercido su derecho a apelar.

Como se observa, no hay actividad de las partes en el trámite de la consulta. Es el legislador, quien sustituye la voluntad de los litigantes y establece que en determinados asuntos las resoluciones sean revisadas de oficio por el superior jerárquico correspondiente.

\subsection{Origen y fundamento de la consulta}

Piedrabuena Richard (1999), sostiene que el origen de la consulta se remonta al derecho antiguo y su fundamento descansa "en la premisa inquisitiva de que las sentencias de los tribunales inferiores debían necesariamente ser revisadas a fin de resguardar el orden público legal, cuyos intereses van más allá que los de las partes litigantes" (p. 427).

En este mismo sentido, Mosquera Ruíz y Maturana Miquel (2010), refiriéndose al antiguo proceso penal, señalan que la consulta se encontraba regulada para un gran número de resoluciones "dado el interés público envuelto en estos asuntos" (p. 123). En efecto, históricamente en el marco de sistemas inquisitivos, esta figura surge como consecuencia de la organización jerárquica del Poder Judicial, la centralización del poder y el control de las decisiones judiciales (Horvitz Lennon y López Masle, 2014 , p. 347). Ello explica la regulación de un régimen recursivo intenso, en donde la apelación jugaba -hasta antes de la reforma procesal penal del 2000- un rol central, pues se trataba de un recurso que procedía contra la generalidad de las resoluciones judiciales y con una causal amplia, cual es el agravio (Carocca Pérez, 2000).

Por ello, se sostiene que la consulta constituye una manifestación de la lógica vertical y jerárquica con que se organiza el Poder Judicial. En una completa descripción acerca del régimen de recursos en el sistema inquisitivo previo a la reforma de 2000, Carocca Pérez (2000) sostiene que la revisión de oficio de importantes y numerosas resoluciones judiciales penales era posible a través "de la añeja e hispánica forma de la consulta, que a estas alturas no puede ser calificada sino como un verdadero fósil jurídico" (p. 303). 
Este trámite, parece justificarse entonces por el carácter jerárquico de la administración de justicia y que finalmente trasunta la necesidad del control del órgano superior respecto del órgano inferior. Según señala Letelier Loyola (2013, p, 158), tras las impugnaciones hay un fundamento político, esto es, el control de la actividad jurisdiccional. En la consulta, este control adquiere aún más fuerza toda vez que prescinde de la actividad de las partes $y$, en tal caso, la competencia del superior jerárquico no queda limitada a los agravios, por lo que se corre el riesgo de un "exceso de poder" por parte del órgano revisor.

\subsection{Características de la consulta}

El desarrollo dogmático de la consulta a nivel nacional es relativamente escaso. Pese a ello, en un intento por caracterizar este trámite procesal, diremos que reúne los elementos que a continuación se mencionan:

\subsubsection{Constituye una manifestación del principio de la oficialidad}

En los casos en que este principio prevalece, tanto el inicio del proceso como la determinación de su objeto dependen de la actuación de ciertos órganos públicos (por ejemplo, el propio tribunal o el Ministerio Publico) (Carocca Pérez, 2003, p. 30). Se contrapone al principio dispositivo donde la iniciativa y acción de los litigantes opera como el motor de arranque del procedimiento, ellos disponen de su interés privado y pueden concurrir o no al sistema buscando satisfacer su pretensión (Carocca Pérez, 2003, p. 28).

El principio de la oficialidad se justifica por el predominio del interés público de ciertos asuntos, en los cuales el legislador ha considerado que el proceso no puede depender solo de la voluntad de las partes.

\subsubsection{Carácter excepcional de la consulta}

En nuestro ordenamiento jurídico actual la consulta constituye una figura excepcional en la estructura del sistema recursivo y, además, su consagración es marginal. Esto último, se debe principalmente a las reformas procesales en materia penal y de familia de inicios de los años 2000, que eliminan este trámite en muchos asuntos. Hoy en día la consulta se contempla solo en cuatro procedimientos especiales, a saber: procedimiento de hacienda regulado en el Código de Procedimiento Civil (1902, art. 748 al 752), procedimiento de constitución de una concesión minera (Ley $\mathrm{N}^{\circ}$ 18.248, 1983, art. 86); amparo económico (Ley №18.971, 1990) y, por último, en materia ambiental, en el caso de ciertas sanciones impuestas por la Superintendencia del Medio Ambiente, como se verá con detalle más adelante. 


\subsubsection{Carácter estricto de la consulta}

El trámite de la consulta debe explicarse por la ausencia de actividad de los litigantes. Así, la consulta no procede cuando las partes han impugnado una determinada resolución judicial. Se expresa también en la o las causales que habilitan su procedencia, como ocurre, por ejemplo, en el procedimiento de hacienda, donde la ley señala que los autos se elevarán en consulta cuando la sentencia sea “...desfavorable al interés fiscal" (Ley N¹.552, 1902, art. 751). Estas definiciones dan lugar a una restricción en su acceso.

\subsection{Algunas notas sobre la naturaleza jurídica de la consulta}

Hemos dicho que la consulta se encuentra íntimamente ligada a los recursos procesales y, en particular, al recurso de apelación.

A partir del concepto de recursos procesales como medio de impugnación cuyo objetivo es enmendar o invalidar las resoluciones judiciales que contienen un vicio o error que causa agravio a los litigantes-, la consulta podría ser clasificada (no sin ciertos resquemores) como una categoría especial dentro del género que constituyen los medios de impugnación de las resoluciones judiciales. Ello, pues este trámite supone que un tribunal superior jerárquico examine una resolución judicial dictada por un tribunal inferior, razón por la cual el asunto en cuestión se conoce dos veces por dos tribunales distintos (principio de la doble instancia).

Sin embargo, la consulta carece de uno de los elementos esenciales de los recursos procesales, cual es, la actividad de las partes. En efecto, ellas son quienes frente a una resolución judicial impugnable y perjudicial a sus intereses solicitan la actuación de la ley a su favor. Desde esa perspectiva, resulta claro que la figura de la consulta no puede ser catalogada como un recurso procesal. Aquí el impulso procesal no recae en los litigantes, sino que es el tribunal quien debe elevar los autos en consulta en virtud de un mandato legal. Tampoco es una vía de impugnación, pues es de la esencia de la impugnación que exista una actividad impugnativa de parte agraviada. Por estas razones, entendemos que no se debe hablar de recurso procesal, sino de una potestad invalidatoria o revocatoria de los tribunales superiores en casos muy específicos.

La consulta supone una revisión de oficio de los tribunales superiores, sin mediar actividad alguna de las partes. Incluso más, la ley parece oponerse a la voluntad de éstas, pues éstas -al no apelar- han renunciado tácitamente a la facultad de impugnar que la ley les otorga. Ello se justifica, como vimos con anterioridad, en el interés público que envuelve a ciertos asuntos que a juicio del legislador es necesario cautelar. 


\section{La consulta en el ordenamiento jurídico chileno}

Las reformas procesales implementadas a partir del año 2000 en adelante, marcan un antes y un después en la presencia de la consulta en nuestro ordenamiento jurídico. Ello se advierte con especial nitidez en el ámbito de la justicia criminal, donde se elimina la consulta de manera absoluta. El antiguo Código de Procedimiento Penal establecía este trámite para una amplia gama de resoluciones judiciales, tales como las sentencias definitivas de primera instancia que imponían penas superiores a un año de presidio, reclusión, confinamiento, extrañamiento o alguna superior a estas; las excarcelaciones concedidas a los reos; las excarcelaciones concedidas en causas por delitos tributarios y en los sobreseimientos definitivos o temporales, entre otras.

En estos casos, la consulta suponía una revisión automática por el superior jerárquico, constituyendo a mediados de los años 90 -de acuerdo a la evidencia empírica de la época- cerca de la mitad de los asuntos conocidos por la Corte de Apelaciones de Santiago (Duce Julio y Riego Ramírez, 2007, p. 505). Diversas razones llevaron al legislador a eliminar esta figura en el marco de un nuevo proceso penal, pero la principal reside en la concepción de un sistema recursivo entendido como una facultad o derecho de las partes, y no como un control jerárquico de las decisiones de los tribunales inferiores por parte de los superiores. El cambio de un sistema inquisitivo por uno acusatorio supuso, entre otras cosas, la desaparición de la doble instancia como objetivo del sistema de recursos y como método de control de la sentencia definitiva, en donde la consulta deja de tener sentido (Carocca Pérez, 2000, p. 306).

En el ámbito civil, en cambio, la presencia de la consulta siempre fue más restringida. Hasta el año 2004 el Código de Procedimiento Civil reguló la consulta para los procedimientos de nulidad de matrimonio y divorcio, de acuerdo a lo consagrado en los artículos 753 y siguientes del referido cuerpo legal. Allí se establecía que cuando la sentencia diera lugar a la nulidad o al divorcio perpetuo, ella debía elevarse en consulta al tribunal superior y si éste "... estima dudosa la legalidad del fallo consultado, retendrá el conocimiento del negocio y procederá como si en realidad se hubiera interpuesto oportunamente apelación, oyendo al ministerio público. En caso contrario, aprobará la sentencia" (Ley № 1.552, 1902, art. 753; artículo derogado por la Ley $\mathrm{N}^{\circ}$ 19.947, 2004, art. 2).

La nueva Ley de Matrimonio Civil (Ley $\left.N^{\circ} 19.947,2004\right)$ elimina los referidos artículos del Código de Procedimiento Civil ${ }^{1}$, manteniendo la figura de la consulta con otra redacción, pero en similares términos:

\footnotetext{
${ }^{1}$ El artículo segundo transitorio de la Ley №19.947 establece: “Deróganse el Título XVII del Libro III del Código de Procedimiento Civil, y los artículos 753 a 757 que lo componen".

Rev. derecho (Coquimbo, En línea) 2021, 28: e3769
} 
Cuando la sentencia que dé lugar a la separación judicial, a la nulidad o al divorcio no sea apelada, deberá elevarse en consulta al tribunal superior, y si él estima dudosa la legalidad del fallo consultado, retendrá el conocimiento del asunto y procederá como si se hubiera interpuesto apelación en su oportunidad. En caso contrario, aprobará la sentencia. (Ley N 19.947, 2004, art. 92; artículo derogado por la Ley $\mathrm{N}^{\circ} 20.286,2008$, art. 2, no. 7)

Un año más tarde, lo anterior entra en contradicción con lo dispuesto en la Ley $N^{\circ} 19.968$ (2004) que crea los Tribunales de Familia, legislación que modifica el régimen recursivo aplicable y donde se regula el recurso de apelación sin que se incluya el trámite de la consulta (Ley $N^{\circ} 19.968,2004$, art. 67, nos. 2 al 5). Finalmente, este trámite desaparece del ámbito familiar con la dictación de la Ley № 20.286 (2008) que modifica la ley de Tribunales de Familia. Allí se deroga el artículo 92 de la Ley $N^{\circ} 19.947$ (2004). Por ello, en estricto rigor, la eliminación de la consulta en los casos de nulidad de matrimonio y divorcio se verifica cuatro años después de la entrada en vigencia de la nueva Ley de Matrimonio Civil (Ley Nº19.947, 2004).

En la actualidad, la figura de la consulta se contempla en el Código de Procedimiento Civil (1902, art. 751) en el procedimiento de hacienda - como ya se indicópara aquellos casos en que la sentencia sea desfavorable al fisco. También se encuentra regulada en el Código de Minería (Ley N 18.248, 1983, art. 86), a propósito de la constitución de una concesión minera y en el recurso de amparo económico respecto de la sentencia definitiva dictada por una corte de apelaciones (Ley $\mathrm{N}^{\circ} 18.971$, 1990). A ello se suma la normativa ambiental, en caso de sanciones de clausura y revocación de una Resolución de Calificación Ambiental, establecida por la Ley Orgánica de la Superintendencia del Medio Ambiente (Ley № 20.417, 2010, art. segundo), con características bien particulares, según se analizará con detalle más adelante.

En el plano político vale la pena señalar que la demora que supone la tramitación de la consulta y, por ende, la tramitación general de las causas, llevó en el año 2007 al senador Antonio Horvath Kiss (Proyecto de Ley, 2007) a presentar un proyecto de ley donde se proponía eliminar el trámite de la consulta para las causas civiles, atendida precisamente la sobrecarga de trabajo de nuestras cortes de apelaciones. Proponía su eliminación para todas aquellas causas que tuvieran un eminente contenido patrimonial, lo que incluía los juicios de hacienda y de amparo económico en las que el actor se encuentre patrocinado por abogado. Se mantenía solo para los casos de separación judicial, nulidad o divorcio en que se pueda ver afectado el interés superior de niños, niñas y adolescentes o un incapaz, lo que implicaba realizar una modificación al artículo 92 de la nueva Ley de Matrimonio Civil (Ley №19.947, 2004), antes señalada.

A continuación, se revisa la regulación para los procedimientos en que la consulta actualmente se contempla en nuestro ordenamiento jurídico. 


\subsection{El procedimiento de hacienda}

El procedimiento de hacienda se aplica para aquellos casos en que el Fisco tiene interés pecuniario, cuyo conocimiento está entregado a los tribunales ordinarios de justicia. Se encuentra regulado en Código de Procedimiento Civil (1902, arts. 748 y 752). En estos casos, actúa en representación del fisco el Consejo de Defensa del Estado, organismo que tiene a su cargo la defensa judicial de los intereses económicos del Estado.

El Código de Procedimiento Civil (1902, art. 751) establece que toda sentencia definitiva de primera instancia que no se apele, se elevará en consulta a la Corte de Apelaciones respectiva, "siempre que sea desfavorable al interés fiscal" (Ley № 1.552, 1902, art. 751). La misma norma, se encarga de señalar que ello ha ocurrido cuando no se acoge totalmente la demanda del Fisco o su reconvención, o cuando no deseche en todas sus partes la demanda deducida contra el Fisco, o la reconvención promovida por el demandado (Ley № 1.552, 1902, art. 751).

En estos casos, el tribunal de alzada debe revisar si la sentencia se encuentra o no ajustada a derecho. Si ello es así, la aprobará sin más trámites, pero en caso contrario, retendrá el conocimiento del negocio y, en su resolución, deberá señalar los puntos que le merecen duda, ordenando traer los autos en relación. La vista de la causa se hará en la misma sala y se limitará estrictamente a los puntos de derecho indicados en la resolución.

Si bien en este procedimiento el legislador no alude a la noción de orden o interés público, es posible deducir que habría afectación de los intereses públicos cada vez que el Fisco es condenado en un juicio de hacienda, pues ello implica la realización de una prestación de carácter económico por parte del Estado.

\subsection{El procedimiento de constitución de una concesión minera}

La concesión minera -regulada por la Ley $N^{\circ} 18.097$, de 1982 y modificada en 1990 y por el Código de Mineria (Ley No 18.248, 1983)-, se define como el derecho que se confiere -por medio de los tribunales ordinarios de justicia- a toda persona para que explore o explote sustancias minerales concesibles que existan dentro del perímetro de un terreno determinado. De acuerdo con la Constitución Política de la República (2005), "La concesión minera obliga al dueño a desarrollar la actividad necesaria para satisfacer el interés público que justifica su otorgamiento" (art. 19, № 24, inc. 7).

La ley, establece que las concesiones mineras se constituyen por resolución judicial dictada en un procedimiento no contencioso ante jueces con competencia en materia civil, siendo aplicable las normas del Código de Procedimiento Civil (1902), salvo algunas excepciones (Ley $N^{\circ} 18.248,1983$, art. 34). 
El Código de Minería (1983) regula el procedimiento a través del cual se puede solicitar este derecho, los requisitos y las etapas a cumplir por los interesados. El trámite de la consulta se establece para aquellos casos en que el juez detecte durante la tramitación del procedimiento no contencioso- el incumplimiento de los requisitos o las actuaciones exigidos por la ley. Si ello ocurre, el juez deberá dictar una sentencia declarando la caducidad de los derechos emanados del pedimento o de la manifestación, ordenando cancelar las inscripciones correspondientes.

Si pese a ello (declaración de caducidad), se dicta luego la sentencia de concesión minera:

... ésta no se entenderá constituida sino una vez que la sentencia sea elevada en consulta a la Corte de Apelaciones y sea confirmada por ésta. Si la Corte aprueba la sentencia, quedará constituida la concesión. Si la revoca, declarará la caducidad de los derechos emanados del pedimento o de la manifestación y ordenará la cancelación de las inscripciones correspondientes. La consulta se verá en cuenta. (Ley N 18.248, 1983, art. 86)

En este caso, el código del ramo supedita la concesión minera al cumplimiento del interés público, lo que podría explicar la inclusión de la consulta en este procedimiento.

\subsection{El procedimiento de amparo económico}

El recurso de amparo económico, es la acción que cualquier persona puede interponer ante una corte de apelaciones a fin de denunciar las infracciones a la Constitución Política de la República (2005, art. 19, N²1), según dispone la Ley $\mathrm{N}^{\circ}$ 18.971 (1990).

Se trata de un mecanismo para cautelar y garantizar la actividad económica, cuyo fin es reforzar la tutela jurisdiccional de la libertad económica o libertad de empresa de los particulares. En otras palabras, busca proteger a los titulares de este derecho constitucional de conductas que entraben o conculquen el derecho a desarrollar cualquier actividad económica lícita, ya sea comercial, industrial, de servicios, etc. (Cárcamo Righetti, 2015).

Cualquier persona -natural o jurídica, incluso también las entidades sin personalidad jurídica- puede interponer el recurso de amparo económico ante la Corte de Apelaciones respectiva, dentro de los seis meses contados desde que se produjo la infracción a la norma constitucional antes señalada.

El artículo único que contiene la Ley No18.971 (1990), establece que el conocimiento de la apelación de la resolución que se pronuncie del amparo económico y de la consulta en caso que la sentencia no sea apelada, corresponde a la Corte Suprema. 
En este caso, la inclusión de la consulta se explicaría porque tanto el derecho a la libertad económica consagrado en la Constitución Política de la República (2005), como el mismo recurso de amparo económico, forman parte de lo que se denomina doctrinariamente como orden público económico (Huidobro Salas, 2010).

A continuación, abordaremos en más detalle la consulta en la normativa ambiental.

\section{La consulta en la Ley de Tribunales Ambientales}

\subsection{Origen de la obligación}

La obligación de elevar en consulta ciertas sanciones que aplique la Superintendencia del Medio Ambiente, no fue parte del proyecto de ley original que envió el Ejecutivo al Congreso, para reformar la institucionalidad ambiental, el 5 de junio de 2008. Su origen, por el contrario, se encuentra en el Protocolo de Acuerdo suscrito con fecha 26 de octubre de 2009 en la Comisión de Medio Ambiente de la Cámara de Diputados. Dicho acuerdo estableció "El compromiso de contar con un Tribunal Ambiental..." (Historia de la Ley $\mathrm{N}^{\circ} 20.417,2018$, p. 933) sobre la base de ciertos ejes, entre los cuales se encuentra el de "...competencias de control previo" en el caso de algunas medidas provisionales y de "...revisión plena y obligatoria (consulta) respecto de las sanciones más graves que pueda aplicar la referida Superintendencia..." (Historia de la Ley $N^{\circ} 20.417,2018$, p. 933). De esta manera, se incluye -por indicación del Ejecutivo- el artículo 57 de la Ley Orgánica de la Superintendencia del Medio Ambiente, "Cuando la Superintendencia aplique las sanciones señaladas en las letras c) y d) del artículo 38, la resolución que las contenga deberá siempre ser elevada en consulta al Tribunal Ambiental" (Ley $N^{\circ} 20.417,2010$, art. segundo, art. 57) y que establece la obligación de elevar en consulta al tribunal ambiental las sanciones de clausura y de revocación de la Resolución de Calificación Ambiental.

En consistencia con el acuerdo adoptado y con lo dispuesto en el artículo 57 de la Ley Orgánica de la Superintendencia del Medio Ambiente, el Proyecto de Ley que "Crea el Tribunal Ambiental" -que envía el Ejecutivo al Congreso con fecha 28 de octubre de 2009- incorpora dentro de las características del tribunal, el que se trate de un órgano con "...modalidades de control" (Historia de la Ley $N^{\circ} 20.600,2018$, p. 7) dentro de las cuales se incluye la "...revisión plena y obligatoria (consulta) cuando la sanción sea la revocación de la Resolución de Calificación Ambiental o la clausura de la empresa..."(Historia de la Ley $\mathrm{N}^{\circ} 20.600,2018$, p. 7). De esta manera, se introduce finalmente dicha competencia específica en la Ley № 20.600 (2012), estableciendo que los Tribunales Ambientales serán competentes para:

Autorizar (...) las resoluciones de la Superintendencia que apliquen las sanciones establecidas en las letras c) y d) del artículo 38 de la misma ley, eleva- 
das en consulta. Será competente para autorizar estas medidas el Tribunal Ambiental del lugar en que las mismas vayan a ser ejecutadas. (art. 17, $\mathrm{N}^{\circ} 4$ )

No hay registro de discusión de fondo en torno a esta figura legal ni durante la tramitación de la Ley Orgánica de la Superintendencia del Medio Ambiente ni de la Ley No 20.600 (2012).

\subsection{Aplicación de la obligación de elevar en consulta las sanciones de la Superintendencia del Medio Ambiente}

Hasta la fecha (septiembre 2019), la Superintendencia del Medio Ambiente ha elevado en consulta a los tribunales ambientales ocho resoluciones sancionatorias, seis de las cuales han debido ser conocidas por el Segundo Tribunal Ambiental, una por el Primero y una por el Tercero. A continuación, se revisarán cronológicamente los antecedentes principales de cada uno de estos casos, con el objeto de analizar cómo se ha aplicado en la práctica esta obligación legal.

\subsubsection{Segundo Tribunal Ambiental}

De los seis casos que se han elevado en consulta al Segundo Tribunal Ambiental de Santiago, desde su entrada en vigencia en 2013 hasta septiembre de 2019, éste se ha pronunciado sobre la legalidad de la sanción impuesta en sólo cuatro oportunidades. En los otros dos casos (Consulta de la Superintendencia del Medio Ambiente sobre Res. Ex. SMA N 695 de fecha 24 de noviembre de 2014, 2015 y Consulta de la Superintendencia del Medio Ambiente sobre Res. Ex. $N^{\circ} 234$, de 17 de marzo de 2016, 2016), estimó que no era procedente pronunciarse sobre la legalidad de la resolución de la Superintendencia debido a que ya existía una reclamación en su contra. En relación con el primer caso, Rol C-3-2014, consistente en la sanción contra "Tecnorec", se trata de la reclamación Robles Pantoja Alberto/Superintendencia del Medio Ambiente (Res. Ex. N 695, de 24 de noviembre de 2014), (2015); en el segundo caso, Rol C-6-2016, consistente en la sanción impuesta al proyecto minero "Maricunga", se trata de la reclamación SCM Compañia Minera Maricunga / Superintendencia del Medio Ambiente (Res. Ex. N571, de 23 de junio 2016) (2017).

Efectivamente, en los cuatro casos de consulta que finalmente fueron resueltos por el tribunal, no se interpuso reclamación en contra de la resolución de la Superintendencia del Medio Ambiente, por lo que el Tribunal procedió a conocer de la consulta y analizar la legalidad de la sanción adoptada, confirmándola en tres de los cuatro casos (Sólo es rechazada en Rol C-2-2013, como se verá más adelante).

Cabe señalar, que todos los casos que la Superintendencia del Medio Ambiente ha elevado en consulta al Segundo Tribunal Ambiental consisten en resoluciones que aplican la clausura como sanción. Se trata de las siguientes resoluciones sancionatorias: 
i) Resolución que impone al infractor "Al Hamd Import Export Ltda" la clausura temporal de las obras correspondientes al proyecto "Plataforma de Almacenamiento II" (Resolución Exenta No 591, 2013)²;

ii) Resolución que impone al infractor "Granja Marina Tornagaleones S.A." la clausura definitiva de las obras del centro de cultivos de salmónidos "Sector Punta Quillaipe" (Resolución Exenta No601, 2013)33;

iii) Resolución que impone a "Tecnorec S.A", titular del proyecto "Planta de Reciclaje de Baterías - EMASA", la sanción de clausura total y temporal del proyecto (Resolución Exenta $\left.\mathrm{N}^{\circ} 695,2014\right)^{4}$;

iv) Resolución que impone a "Empresa Minera Española Chile Ltda" la sanción de clausura total y definitiva de sus actividades productivas ubicadas en el Cerro el Roble de la comuna de Maipú (Resolución Exenta № 432, 2015)

v) Resolución que impone a "Anglo American Sur S.A." la clausura total y temporal del "Depósito de Estériles Donoso" (Resolución Exenta № 363, 2015) ${ }^{6}$; y

vi) Resolución que impone la sanción de clausura definitiva del sector de pozos de extracción de aguas, ubicados en el Corredor Biológico "Pantanillo-Ciénaga Redonda", del proyecto minero "Maricunga" y, resolución que resuelve la reposición interpuesta en contra de la resolución anterior y que modificó la sanción estableciendo la forma, condiciones, requisitos y gradualidad en la implementa-

\footnotetext{
${ }^{2}$ La infracción consistió en ejecutar obras correspondientes a la etapa de construcción del proyecto, mientras se encontraba en desarrollo la evaluación de impacto ambiental del mismo. Es decir, se configuró la infracción del artículo 35 letra b) de la Ley Orgánica de la Superintendencia del Medio Ambiente, la cual fue clasificada como grave, en virtud de lo dispuesto en el artículo 36 №2 letra d) de la misma ley (Rol C-1-2013).

${ }^{3}$ La infracción consistió en realizar las actividades del centro de cultivos 800 metros fuera del lugar autorizado por la Resolución de Calificación Ambiental. La Superintendencia del Medio Ambiente configuró la infracción del artículo 35 letra b) y la clasificó como grave en virtud del artículo №36.2. d) (Rol C-2-2013).

${ }^{4}$ La infracción por la cual se impone la sanción que se consulta corresponde al cargo no 18 del proceso sancionatorio, consistente en la ejecución de una modificación de un proyecto y el desarrollo de actividades, para los que la ley exige Resolución de Calificación Ambiental, sin contar con ella. La Superintendencia del Medio Ambiente configura la infracción del artículo 35 letra b), la cual fue clasificada como gravísima, en virtud de lo dispuesto en el artículo 36 №1 letra f) de la Ley Orgánica de la Superintendencia del Medio Ambiente. Durante el procedimiento sancionatorio se adoptaron varias medidas provisionales de detención de funcionamiento de la instalación (Rol C-3-2014).

${ }^{5}$ La infracción consistió en realizar un proyecto de desarrollo minero sin contar con la Resolución de Calificación Ambiental que autorice a efectuar dichas labores, configurándose la infracción del artículo 35 letra b) de la Ley Orgánica de la Superintendencia del Medio Ambiente, clasificada como gravísima, en virtud de lo dispuesto en el artículo 36 №1 letra f) de la misma ley. Durante el proceso sancionatorio se adoptaron medidas provisionales de clausura temporal de las faenas (Rol C-4-2015).

${ }^{6}$ La infracción por la cual se impone la sanción de clausura temporal del Depósito de Estériles Donoso corresponde al cargo $\mathrm{N}^{\circ} 2$ del proceso sancionatorio, esto es, no haber resuelto el origen del drenaje ácido existente ni materializar una solución permanente que resuelva la presencia de drenaje ácido al pie del depósito de estériles. La infracción constituye un incumplimiento a la Resolución de Calificación Ambiental del proyecto, por lo que se configura la infracción del artículo 35 letra a) de la Ley Orgánica de la Superintendencia del Medio Ambiente, la que es clasificada como grave en virtud de lo dispuesto en el artículo 36 №2 letra e). La sanción de clausura temporal quedó sujeta a la condición de implementar en un plazo de un año -contado desde la obtención de los permisos necesarios- una solución definitiva a la generación de drenajes ácidos (Rol C-5-2015).
} 
ción de la sanción de clausura definitiva (Resolución Exenta № 234, 2016 y Resolución Exenta №571, 2016)ำ.

Tal como se indicó, el Segundo Tribunal Ambiental confirmó la legalidad de la sanción adoptada en tres casos, correspondientes a la sanción de clausura de los proyectos "Plataforma de Almacenamiento II" (Consulta de la Superintendencia del Medio Ambiente sobre Res. Ex. SMA N 591, de 17 de junio de 2013, 2013) “Minera Española" (Consulta de la Superintendencia del Medio Ambiente sobre Res. Ex. $N^{\circ} 432$, de 01 de junio de 2015, 2015) y "Depósito Estériles Donoso" (Consulta de la Superintendencia del Medio Ambiente sobre Res. Ex. SMA N 363 de 04 de mayo de 2015, 2015). El razonamiento expresado por el tribunal en cada uno de estos casos se concentra en la revisión de la tercera fase del ejercicio de la potestad sancionadora de la Superintendencia del Medio Ambiente, esto es, la determinación de la sanción específica aplicable, la cual se enmarca dentro de la potestad discrecional de dicha autoridad ${ }^{8}$.

En el primer caso, el tribunal considera que se ha llevado a cabo una correcta aplicación de los principios de proporcionalidad y razonabilidad, sin perjuicio que no justifica dicha conclusión. En el caso de Minera Española, sin embargo, el tribunal se refiere expresamente a las consideraciones de la Superintendencia del Medio Ambiente para imponer la clausura definitiva señalando:

...que la imposición de una multa -de acuerdo con el Superintendente- no era suficiente para cumplir el objetivo de disuasión, por cuanto la gravedad de los hechos hacía necesario tomar acciones para el resguardo del medio ambiente, y que 'un presupuesto base para que el daño generado tenga el carácter de reparable, es el cese definitivo de las actividades mineras por parte del infractor'. (Consulta de la Superintendencia del Medio Ambiente sobre Res. Ex. $N^{\circ} 432$, de 01 de junio de 2015, 2015, cons. 7)

Sostiene que la potestad discrecional para escoger una sanción requiere de la debida motivación, concluyendo que el razonamiento que tuvo la Superintendencia del Medio Ambiente para imponer la clausura definitiva de la faena minera, es suficiente. Por su parte, en el tercer caso en análisis, en el cual la Superintendencia del Medio Ambiente impone a Anglo American una sanción de clausura temporal y total del Depósito de Estériles Donoso, el tribunal revisa una por una las circunstancias del

\footnotetext{
${ }^{7}$ La infracción por la cual se impone la sanción de clausura consiste en "la omisión de ejecutar las acciones necesarias para hacerse cargo de los impactos ambientales no previstos consistentes en la disminución del nivel freático en la cuenca Pantanilla-Ciénaga Redonda y el consecuente desecamiento de, al menos 70 ha de humedales ubicados en el Complejo Lacustre Laguna del Negro Francisco y Laguna Santa Rosa y el riesgo inminente de expansión del área afectada a aproximadamente 73 ha adicionales de humedales, no obstante encontrarse implementada la medida de conexión de los pozos de extracción con las vegas de Pantanillo, contemplada en la RCA que autoriza el proyecto". La infracción constituye un incumplimiento a la Resolución de Calificación Ambiental, por lo que se configura la infracción del artículo 35 letra a) de la Ley Orgánica de la Superintendencia del Medio Ambiente, la que es clasificada como gravísima en virtud de lo dispuesto en el artículo 36 No1 letra a) (Rol C-6-2016).

${ }^{8}$ La primera fase, consistente en la configuración de la infracción, y la segunda, referida a su clasificación (leve, grave o gravísima), no son objeto de análisis en la revisión de legalidad que hace el tribunal.
} 
artículo 40 de la Ley Orgánica de la Superintendencia del Medio Ambiente (2010) que fueron consideradas por la Superintendencia del Medio Ambiente para determinar la sanción. A su vez, expresamente releva dos criterios utilizados por la autoridad para imponer la sanción en cuestión: "i) cuando las sanciones pecuniarias no son suficientes para cumplir el objetivo de disuasión; $y$, ii) cuando no son capaces de corregir los efectos de la infracción al bien jurídico". (Consulta de la Superintendencia del Medio Ambiente sobre Res. Ex. SMA N ${ }^{\circ} 363$ de 04 de mayo de 2015, 2015, cons. 13). Por último, considera que para fundamentar la sanción específica la Superintendencia del Medio Ambiente tuvo en cuenta que el beneficio económico obtenido de la infracción excede el máximo legal de una multa por infracción grave. Así, sostiene que la motivación de la aplicación de las circunstancias del artículo 40, permiten al tribunal concluir que el razonamiento que tuvo la Superintendencia del Medio Ambiente es suficiente para imponer la sanción de clausura.

A diferencia de los tres casos anteriores, en la causa relativa al centro de cultivos de salmónidos de Tornagaleones (Consulta de la Superintendencia del Medio Ambiente sobre Res. Ex. SMA N601, de 19 de junio de 2013, 2013) el tribunal rechazó la sanción consultada, ordenando devolver los antecedentes a la Superintendencia del Medio Ambiente para que resolviera nuevamente sobre la sanción a imponer al infractor. En este caso, el tribunal revisa las tres fases del ejercicio de la potestad sancionadora de la Superintendencia del Medio Ambiente, estableciendo que considera incorrecta la tipificación y clasificación de la infracción realizada por la autoridad, estimando que los hechos infraccionales constituyen en realidad un incumplimiento de la Resolución de Calificación Ambiental del proyecto, al no cumplir las condiciones de ubicación autorizadas para el centro de cultivos debiéndose haber configurado la infracción del artículo 35 letra a) de la Ley Orgánica de la Superintendencia del Medio Ambiente (2010), y no la elusión al Sistema de Evaluación de Impacto Ambiental, contemplada en el artículo 35 letra b). Agrega que la incorrecta tipificación trajo consigo otra consecuencia, que es no haber considerado la concurrencia de alguna de las otras circunstancias del artículo 36, que podrían haber modificado la clasificación de la infracción. Además, el tribunal sostiene que no comparte la sanción adoptada, puesto que al decretar la clausura definitiva del centro de cultivo le concede la naturaleza de sanción a una actuación propia de la regularización del emplazamiento de la actividad, por lo que la sanción se tornaría superflua, no recibiendo el infractor ninguna consecuencia desfavorable por vulnerar el ordenamiento jurídico. Por el contrario, señala el tribunal, "... el mensaje que se entrega al infractor - prevención especial - no es precisamente disuasivo, ya que sabrá que, ante una infracción similar, le bastará con cerrar el centro y trasladarse al lugar autorizado" (Consulta de la Superintendencia del Medio Ambiente sobre Res. Ex. SMA N601, de 19 de junio de 2013, 2013, cons. 7). Por último, sostiene que la sanción no produce un efecto de carácter retributivo al infractor, ni cumple con los fines de prevención general que asiste a las sanciones.

Por último, en relación con los dos casos en que el Segundo Tribunal AmbienRev. derecho (Coquimbo, En línea) 2021, 28: e3769 
tal decidió no pronunciarse sobre la consulta - debido a la existencia de reclamaciones pendientes ante el mismo tribunal contra las mismas resoluciones -, es llamativo que en ninguno de los dos casos el tribunal, en su sentencia definitiva, se llegó a pronunciar sobre la legalidad de la sanción de clausura impuesta por la Superintendencia del Medio Ambiente. En efecto, por diversas razones, en ambos casos la sentencia definitiva que resuelve la reclamación interpuesta se pronuncia sobre otros aspectos de la resolución sancionatoria de la Superintendencia del Medio Ambiente, y no sobre la sanción de clausura. Es decir, la decisión de no pronunciarse sobre la consulta por haber perdido su objeto al interponerse una reclamación no necesariamente permite cumplir con el objetivo de la consulta, esto es, controlar la legalidad de la sanción impuesta.

En efecto, en el caso "Tecnorec", la reclamación fue interpuesta por un interesado en el proceso sancionatorio - es decir, no fue interpuesta por el sancionado -, el cual no impugnó la sanción de clausura dentro de sus alegaciones, por lo que el Tribunal finalmente en su sentencia definitiva (Robles Pantoja Alberto/Superintendencia del Medio Ambiente [Res. Ex. N695, de 24 de noviembre de 2014], 2015) no se pronuncia sobre la legalidad de la sanción, y al no haber sido objeto de casación, tampoco hubo posterior pronunciamiento de la Corte Suprema.

En el caso "Maricunga", por su parte, es el titular del proyecto minero sancionado con la clausura definitiva de los pozos de extracción de agua, quien interpone reclamación ante el Segundo Tribunal Ambiental. Sin embargo, en la sentencia definitiva (SCM Compañia Minera Maricunga / Superintendencia del Medio Ambiente [Res. Ex. $N^{\circ}$ 571, de 23 de junio 2016], 2017) que resuelve dicha reclamación, el tribunal rechaza las alegaciones de la empresa por considerar que incurrió en desviación procesal, al hacer valer en su recurso de reclamación judicial una pretensión distinta a la planteada en sede administrativa, vía reposición. En efecto, en sede administrativa la minera había alegado la imposibilidad de cumplir la sanción de clausura en los términos impuestos por la Superintendencia del Medio Ambiente, en cambio, en sede judicial reclamó la ilegalidad de la resolución sancionatoria por una infracción al principio de tipicidad en la formulación de cargos. El tribunal ambiental consideró que las pretensiones fueron distintas en ambas sedes, lo que implicaría una desviación procesal, doctrina que se basa en el principio de congruencia y que impediría cumplir con el carácter revisor del contencioso-administrativo. El titular interpuso recurso de casación en la forma y en el fondo ante la Corte Suprema, los cuales fueron desestimados confirmando la tesis de la desviación procesal y la inexistencia de agravio para el recurrente (Sociedad Contractual Minera Compañía Minera Maricunga con Superintendencia del Medio Ambiente, 2018).

Cabe señalar, sin embargo, que en este último caso la Corte señaló que "...el hecho de no haberse verificado la consulta sobre el fondo del asunto podría haber sido considerado como un vicio procesal" (Sociedad Contractual Minera Compañía Minera 
Maricunga con Superintendencia del Medio Ambiente, 2018, cons. 9). A su vez, en un voto de prevención - del Ministro Prado Puga -, se sostuvo que no se cumplió con el control de legalidad que impone la ley al Tribunal Ambiental a través de la consulta (Sociedad Contractual Minera Compañía Minera Maricunga con Superintendencia del Medio Ambiente, 2018).

\subsubsection{Primer Tribunal Ambiental}

La Superintendencia del Medio Ambiente ha elevado sólo una resolución sancionatoria en consulta al Primer Tribunal Ambiental de Antofagasta (Superintendencia del Medio Ambiente con Compañía Minera Nevada Spa, 2018), esta es, la resolución que puso término al procedimiento administrativo sancionatorio seguido contra Compañía Minera Nevada Spa, en relación al proyecto minero Pascua-Lama (Resolución Exenta No 72, 2018). Dicha resolución sancionatoria impuso, entre otras sanciones, cinco sanciones de clausura definitiva de la faena minera?

El 12 de octubre de 2018 el tribunal resolvió el trámite de consulta en cuestión, confirmando la configuración de los cinco cargos y la clasificación de cuatro de ellos, pero aprobando la sanción de clausura definitiva sólo respecto del cargo №7, ordenándose a la Superintendencia del Medio Ambiente, por lo tanto, la reponderación de las otras cuatro sanciones (Superintendencia del Medio Ambiente con Compañía Minera Nevada Spa, 2018) ${ }^{10}$. El razonamiento del tribunal para llegar a esta decisión se expresa de manera pormenorizada en la resolución, revisando cada uno de los antecedentes jurídicos y técnicos del procedimiento sancionatorio que permitieron a la Superintendencia del Medio Ambiente fundamentar la configuración, clasificación y determinación de la sanción de clausura para cada una de las infracciones.

Cabe señalar que, tanto la empresa (Compañía Minera Nevada Spa con Superintendencia del Medio Ambiente, 2018) como uno de los interesados (Agrícola Dos Hermanos Limitada y Otros con Superintendencia del Medio Ambiente, 2018) en el pro-

\footnotetext{
${ }^{9}$ Las infracciones sancionadas con clausura fueron: i) la construcción de obras en sitios no autorizados por la Resolución de Calificación Ambiental generando daño ambiental irreparable al Ecosistema Altoandino, en particular a formaciones vegetacionales de vegas y Azorella madrepórica (cargo n०4, infracción artículo 35 letra a) calificada como gravísima en virtud del artículo 36 №1 letra a); ii) incumplimiento parcial a las obligaciones contenidas en el Plan de Monitoreo de Glaciares, en los siguientes componentes: Albedo; MP; Temperatura; Estudios de permafrost; Balance de Masa Combinado; Plan Comunicacional (cargo n`7, artículo 35 letra a, calificada como grave en virtud de artículo 36 №2 letra e); iii) construcción de la obra de salida del Canal Perimetral Norte Inferior, en términos distintos a los autorizados en la Resolución de Calificación Ambiental, generando con ello, un daño ambiental irreparable en el Ecosistema Altoandino (cargo n²3.2, artículo 35 letra a), calificada como gravísima en virtud del artículo 36 №1 letra a); iv) no haber activado el Plan de Alerta Temprana y Respuesta de calidad de las aguas, en el mes de enero de 2013, habiéndose constatado niveles de emergencia (cargo n०23.9, artículo 35 letra a) calificado como grave en virtud del artículo 36 №2 letra e); v) la descarga de aguas de contacto al río Estrecho que no cumplen con los objetivos de calidad de aguas establecido en la Resolución de Calificación Ambiental (cargo n²3.11, artículo 35 letra a) calificado como grave en virtud del artículo 36 №2 letras b y e).

${ }^{10}$ Cabe señalar que en opinión disidente el Ministro Guevara estuvo por rechazar la sanción de clausura definitiva también del cargo $\mathrm{N}^{\circ} 7$.
} 
cedimiento administrativo sancionatorio, interpusieron reclamaciones ante el mismo tribunal en contra de la resolución sancionatoria, con fechas 3 y 5 de febrero de 2018, respectivamente. Con posterioridad, ambos recurrentes solicitaron hacerse parte en el proceso de consulta - lo que no les fue autorizado - $y$, también, la acumulación de la consulta a las reclamaciones interpuestas - lo que a su vez les fue negado-. Por su parte, la Superintendencia del Medio Ambiente con fecha 20 de marzo de 2018 solicitó al tribunal dejar sin efecto el trámite de la consulta, para conocer de las reclamaciones deducidas contra la Resolución $\mathrm{N}^{\circ} 72$, petición que tampoco tuvo éxito. En este sentido, cabe resaltar lo que determinó el Primer Tribunal Ambiental al pronunciarse sobre la solicitud de la Superintendencia del Medio Ambiente, indicando que:

... las resoluciones que impongan las sanciones referidas deberán siempre ser elevadas en consulta al tribunal ambiental. Teniendo dicha norma a juicio de estos sentenciadores, el carácter de orden público, y por ende, irrenunciable por las partes, se resuelve no dar lugar a lo solicitado por la Superintendencia del Medio Ambiente. (Superintendencia del Medio Ambiente con Compañía Minera Nevada Spa, marzo 2018)

Sin embargo, el caso no terminó allí, ya que el recurrente Sociedad Agrícola Dos Hermanos presentó recurso de queja ante la Corte Suprema, contra los ministros que dictaron la resolución de 12 de octubre de 2018 del Primer Tribunal Ambiental, el que fue acogido con fecha 14 de marzo de 2019, ordenándose:

... que la consulta de la Resolución $N^{\circ} 72$ de 17 de enero de 2018 dictada por la Superintendencia del Medio Ambiente y las reclamaciones deducidas en contra de la misma sean conocidas en una misma audiencia, acumuladas o una en pos de otra, y falladas por Tribunal no inhabilitado. (Agrícola Dos Hermanos Limitada con Ministros del Primer Tribunal Ambiental de Antofagasta, 2019, cons. 10)

Cabe señalar que, con posterioridad a esta sentencia, el Primer Tribunal proveyó la solicitud de la Superintendencia del Medio Ambiente en que solicitaba dejar sin efecto el trámite de la consulta, acogiendo dicha petición por resultar inoficioso pronunciarse al respecto (Superintendencia del Medio Ambiente con Compañía Minera Nevada Spa, 2019).

\subsubsection{Tercer Tribunal Ambiental}

El Tercer Tribunal Ambiental de Valdivia es el único de los tribunales ambientales que ha adoptado un autoacordado en materia de la consulta, estableciendo la forma y los requisitos que debe cumplir la Superintendencia del Medio Ambiente para elevarlas al tribunal. De esta manera señala que:

...Las resoluciones de la Superintendencia del Medio Ambiente que apliquen las sanciones establecidas en las letras c) y d) del artículo 38 del artículo segundo de la Ley 20.417, que deban ser elevadas en consulta a este Tribunal para su autorización, lo serán en forma previa a su notificación a los intere- 
sados, adjuntando copia autentificada del expediente administrativo completo y debidamente foliado que sirvió de base para dictar el acto, de conformidad a lo señalado en la Ley $N^{\circ} 19.880$. Recibidos los antecedentes, el tribunal revisará la resolución en cuenta. (Acta de Sesión Extraordinaria N², 2018)

El Acta de 2013, disponía respecto de la consulta, que:

Las resoluciones de la Superintendencia del Medio Ambiente que apliquen las sanciones establecidas en las letras c) y d) del artículo 38 de la Ley 20.417, deberán ser remitidas al Tribunal Ambiental dentro de tercer día desde su notificación, para su consulta. Recibidos los autos, el tribunal revisará la resolución en cuenta. (Acta de Sesión Extraordinaria N³, 2013, acord. 4).

La Resolución Exenta № 411 (2018) ${ }^{11}$ que pone término al procedimiento administrativo sancionatorio seguido en contra de Agrícola y Frutícola Veneto Ltda., imponiendo la sanción de clausura definitiva al Plantel de Cerdos Santa Josefina, fue elevada en consulta al tribunal con fecha 19 de abril de $2018^{12}$. El tribunal, en su resolución de fecha 9 de mayo de 2018 (Consulta de la Superintendencia del Medio Ambiente sobre Resolución Exenta $N^{\circ} 411$, de 5 de abril de 2018, 2018) autoriza la sanción, a pesar de establecer que el expediente acompañado no se encontraba completo. El razonamiento del tribunal es que se trató de vicios que no afectaron la validez del acto administrativo y que, dada la naturaleza de los hechos sancionados, se requería de una acción inmediata y efectiva para proteger el medio ambiente.

Cabe señalar que, con fecha 15 de mayo de 2018, la Superintendencia del Medio Ambiente dicta una nueva resolución (Resolución Exenta № 561, 2018) con el objeto de poner término al procedimiento administrativo y cumplir con el nuevo autoacordado del tribunal en la materia, notificando al infractor la resolución del tribunal que autoriza la sanción de clausura definitiva. Sin perjuicio de lo anterior, el infractor interpuso reclamación ante el Tercer Tribunal Ambiental, también con fecha 15 de mayo, en contra de la primera resolución, la que fue declarada inadmisible debido a que debió presentarse contra el acto terminal del procedimiento, esto es, la segunda resolución que cumple con el autoacordado. La empresa decide, sin embargo, no reclamar en contra de esta última resolución.

\footnotetext{
${ }^{11}$ Notificada al infractor con fecha 17 de abril de 2018.

${ }^{12}$ La infracción sancionada con clausura fue el cargo $n^{\circ} 1$ consistente en la elusión al Sistema de Evaluación de Impacto Ambiental, por la operación de un plantel de cerdos con capacidad aproximada de 7.800 animales porcinos, sin contar con Resolución de Calificación Ambiental favorable, configurando la infracción del artículo 35 letra b) de la Ley Orgánica de la Superintendencia del Medio Ambiente, la que fue calificada como grave en virtud de los dispuesto en el artículo 36 №2 letra d).
} 


\section{Análisis de la aplicación de la consulta por los tribunales ambien- tales}

El Tercer Tribunal Ambiental, en su resolución que autoriza la sanción de clausura impuesta contra el Plantel de Cerdos Santa Josefina, sostiene que

... la LOSMA y la LTA no establecen los aspectos que deben ser revisados por los Tribunales Ambientales para autorizar las sanciones de clausura temporal o definitiva, y de revocación de la resolución de calificación ambiental impuestas por la SMA, la historia fidedigna del establecimiento de la LTA indica que la revisión que le compete a los Tribunales Ambientales en esta materia debe ser plena. De este modo, la revisión de esta sede jurisdiccional debe abarcar tanto el procedimiento como los hechos y el derecho aplicado en la resolución sancionatoria, incluyendo, desde luego, la proporcionalidad de la sanción. Esta revisión intensa cobra sentido, respecto al diseño institucional del sistema, el que dispuso a los Tribunales Ambientales como contrapeso de las potestades de la SMA, especialmente respecto de la aplicación de las sanciones más graves. Lo anterior, no obstante, una futura pretensión anulatoria que pueda ejercer el sancionado. (Consulta de la Superintendencia del Medio Ambiente sobre Resolución Exenta $N^{\circ}$ 411, de 5 de abril de 2018, 2018, cons. 2)

Esta interpretación del alcance del control judicial de las sanciones de la Superintendencia del Medio Ambiente que deben ser elevadas en consulta, ha sido consistente por parte de los tres tribunales. Es decir, todos concuerdan en que la revisión judicial en la consulta es plena, constituyendo una revisión intensa que permite volver a considerar los hechos y el derecho, pudiendo por lo tanto el tribunal ambiental anular lo resuelto por la Superintendencia del Medio Ambiente, en lo que dice relación tanto con la configuración y clasificación de la infracción, como en la determinación de la sanción específica aplicable.

Sin embargo, hay otros aspectos que se han interpretado de manera divergente por los tribunales, tales como el procedimiento aplicable al trámite o la oportunidad en que la sanción consultada produce efectos. A continuación, examinaremos dichos aspectos. Luego, terminaremos esta sección con un análisis acerca del interés público involucrado en el trámite de la consulta - $y$, en particular, en la consulta de la sanción ambiental - el cual ha sido invocado como fundamento de este trámite procesal.

\subsection{Procedimiento aplicable al trámite de la consulta}

La Ley № 20.600 (2012) no ha establecido normas que regulen el procedimiento aplicable a la consulta, por lo que los tribunales ambientales han establecido diversas soluciones al problema que se plantea para regular la oportunidad de su pronunciamiento. 
Para el Segundo Tribunal Ambiental, la consulta sólo aplica una vez vencido el plazo para la impugnación administrativa, en cuyo caso, debe elevarse en consulta la resolución final administrativa al tribunal. A su vez, para el mismo tribunal, la consulta pierde objeto en caso que se interponga reclamación judicial contra la resolución sancionatoria, en cuyo caso el tribunal no se pronunciará sobre la consulta y sólo resolverá la reclamación. Por el contrario, para el Primer Tribunal Ambiental, la consulta reviste un interés público que exige al tribunal proceder a su pronunciamiento en primer lugar, relegando las eventuales reclamaciones contra la resolución sancionatoria a un segundo plano. El Tercer Tribunal Ambiental, por último, considera la consulta como un trámite que debe cumplirse antes de entrar en vigencia la resolución administrativa sancionatoria, de manera que debe elevarse en consulta con anterioridad a su notificación al infractor y a la consiguiente posible impugnación, ya sea administrativa o judicial.

Nos parece que el criterio aplicado por el Segundo Tribunal Ambiental es correcto y se ajusta a la finalidad del trámite de la consulta, esto es, la revisión de ciertas resoluciones "judiciales"- aunque en este caso se trate de una resolución "administrativa" -, cuando las partes no han ejercido los recursos procesales previstos por la ley ante los tribunales correspondientes. Por tanto, si existe una impugnación en contra de una determinada resolución de la Superintendencia del Medio Ambiente que debe ser conocida por el tribunal ambiental, no será entonces procedente que dicho tribunal se pronuncie sobre la consulta.

Esta tesis fue ratificada por la Corte Suprema, al pronunciarse sobre el recurso de casación en la forma y en el fondo interpuesto en contra de la sentencia dictada por el Segundo Tribunal Ambiental, que rechazó la reclamación deducida contra la resolución sancionatoria dictada por la Superintendencia del Medio Ambiente contra el proyecto minero Maricunga. Allí sostuvo que "...el obrar del Tribunal Ambiental se ajusta a derecho y al principio de economía procesal al estimar que el trámite [consulta] perdió su objeto..." (Sociedad Contractual Minera Compañía Minera Maricunga con Superintendencia del Medio Ambiente, 2018, cons. 9). Luego, citando al profesor Cristian Maturana, el fallo señala que la consulta:

'no constituye una instancia ni un recurso, sino que un trámite procesal de orden público establecido por el legislador, en virtud del cual se vela por el resguardo de los intereses públicos o sociales que pueden verse comprometidos en un proceso, consagrado para permitir que se revise el fallo de un tribunal de primera instancia por el superior para el evento que no se haya revisado por la vía del recurso de apelación' (Sociedad Contractual Minera Compañía Minera Maricunga con Superintendencia del Medio Ambiente, 2018, cons. 9; citando a Cristian Maturana, 2007).

Ahora bien, es necesario señalar que este fallo fue objeto de una prevención por parte del Ministro Arturo Prado Puga (Sociedad Contractual Minera Compañía Minera Ma- 
ricunga con Superintendencia del Medio Ambiente, 2018, prevención 5), quien estuvo por anular de oficio la resolución del Segundo Tribunal Ambiental que desestimó la consulta y, en consecuencia, la sentencia que se impugnó por vía de casación, ya que este tribunal habría desatendido el mandato del legislador al constreñir su competencia y relegar el control de legalidad a los aspectos que proponen las partes. Para fundamentar su posición, Prado Puga cita a la abogada Marie Claude Plumer, quien ha sostenido que cuando se presente una reclamación en contra de una resolución respecto de la cual proceda la consulta, ambos trámites deben acumularse y resolverse en forma.

En el mismo sentido de la sentencia de casación del caso Maricunga, la Corte Suprema resuelve con ocasión del recurso de queja presentado contra los ministros del Primer Tribunal Ambiental, que "...la consulta cobra entidad propia en todo cuanto la determinación sujeta al trámite, no ha sido impugnada y no llega al conocimiento jurisdiccional a instancia de parte mediante el recurso pertinente". (Agrícola Dos Hermanos Limitada con Ministros del Primer Tribunal Ambiental de Antofagasta, 2019, cons. 9). Y agrega que, aunque no hay solución legal expresa, ésta;

...puede encontrarse en la aplicación de principios procesales como el de economía procesal y de imparcialidad, pues no parece lógico que una misma decisión deba ser debatida en procedimientos, oportunidades y magistrados diferentes, distrayendo recursos importantes como los que implica el conocimiento de una materia ambiental (...) y, más importante aún es que una resolución no puede ser conocida en el fondo dos veces por el mismo tribunal, pues ello llevaría necesariamente a concluir que, en la segunda oportunidad, su imparcialidad esté afectada indiscutiblemente por haber emitido pronunciamiento, con conocimiento de causa, sobre la cuestión debatida. (Agrícola Dos Hermanos Limitada con Ministros del Primer Tribunal Ambiental de Antofagasta, 2019, cons. 9)

Así, sostiene que los procedimientos de consulta y reclamación judicial deben ser objeto de un mismo pronunciamiento conjunto "...o en una misma audiencia, uno en pos del otro (...) [evitando] eventuales contradicciones, implicancias y economizando recursos materiales y humanos" (Agrícola Dos Hermanos Limitada con Ministros del Primer Tribunal Ambiental de Antofagasta, 2019, cons. 9).

Sin perjuicio que lo sostenido por el Segundo Tribunal Ambiental y la Corte Suprema, se ajusta a lo que consideramos debe entenderse como el procedimiento correcto aplicable al trámite de la consulta, se podría criticar esta posición - tal como lo hace el voto de prevención en el primer fallo de la Corte Suprema - en base a la experiencia hasta ahora recogida. En efecto, en los casos en que las reclamaciones judiciales se han referido a otros aspectos de la decisión administrativa sancionatoria, es decir, no incluyeron un cuestionamiento específico a la sanción de la Superintendencia del Medio Ambiente, en la práctica no ha existido una autorización o revisión judicial de la sanción, requisito que exige la ley al consagrar la consulta. Nos parece 
que esta crítica, sin embargo, no se sostiene cuando se entiende la consulta como un trámite procesal que constituye una revisión de oficio, que opera sólo en el caso que no se ejerza el derecho a reclamar, derecho que corresponde a la parte afectada.

Ahora bien, en relación con la postura asumida por el Tercer Tribunal Ambiental y la dictación de un auto acordado para regular la aplicación del trámite de la consulta, cabe señalar lo siguiente. Dicha decisión se enmarca dentro de las facultades económicas de los tribunales de alzada en el ejercicio de la función jurisdiccional, que les otorga la potestad de dictar instructivos o circulares tendientes a obtener una mejor y pronta administración de justicia. Estas facultades, encuentran su fundamento normativo en Constitución Política de la República $(2005$, art. 82) y en el artículo 3 del Código Orgánico de Tribunales (Ley № 7.421, 1943).

El auto acordado del Tercer Tribunal Ambiental establece - como ya se mencionó - que:

...Las resoluciones de la Superintendencia del Medio Ambiente que apliquen las sanciones establecidas en las letras c) y d) del artículo 38 del artículo segundo de la Ley 20.417, que deban ser elevadas en consulta a este Tribunal para su autorización, lo serán en forma previa a su notificación a los interesados, adjuntando copia autentificada del expediente administrativo completo y debidamente foliado que sirvió de base para dictar el acto, de conformidad a lo señalado en la Ley $N^{\circ} 19.880$. Recibidos los antecedentes, el tribunal revisará la resolución en cuenta. (Acta de Sesión Extraordinaria N², 2018)

Lo que llama la atención de este instructivo, es que establezca que los autos se elevarán en consulta antes de que la resolución sancionatoria sea notificada a las partes. Llama la atención, porque esta norma altera una de las principales reglas sobre las actuaciones judiciales que contiene el Código de Procedimiento Civil (1902), a propósito de las notificaciones judiciales. Como sabemos, las notificaciones son actos de comunicación (Couture Etcheverry, 2016, p. 168) que tienen como finalidad dar eficacia a las resoluciones judiciales, eso significa que estas solo producen efectos en virtud de una notificación realizada con arreglo a la ley, tal como señala expresamente el Código de Procedimiento Civil (1902, art. 38), salvo algunas excepciones. Su relevancia radica en asegurar el derecho a la defensa de las partes, permitiendo la contradicción (Bordalí Salamanca et al., 2016, p. 122). De este modo, las decisiones judiciales no pueden ser adoptadas sin previo traslado a la parte contra la cual se pide, 0 sin que se le otorgue derecho a defensa, y para ello requieren que se haya dictado una resolución judicial y que exista un funcionario judicial que practique la notificación.

Por ello resulta llamativo que el auto acordado dictado por el Tercer Tribunal Ambiental prescinda de esta norma, y otorgue eficacia a una resolución sin que ella haya sido notificada a las partes. Si bien se trata de una resolución administrativa, es 
importante recordar que la Ley № 20.600 (2012, art. 47) señala que a los procedimientos establecidos en esta ley se les aplicarán, supletoriamente, las disposiciones contenidas en los Libros I y II del Código de Procedimiento Civil, por tanto, podría ser aplicable aquí el mismo criterio contenido en el Código de Procedimiento Civil respecto de las notificaciones. Por otra parte, el referido auto acordado parece también prescindir de la voluntad de las partes y autoriza realizar una gestión de la relevancia de la consulta, sin darles previamente traslado. Ellas podrían tener la intención de impugnar la referida resolución, caso en el cual -como ya se ha manifestado- no habría necesidad de elevar los autos en consulta.

Con todo, cabe señalar que en los últimos años se ha dado un intenso cuestionamiento sobre el uso de los auto acordados por la Corte Suprema por parte de los propios jueces, a través de la Asociación Nacional de Magistrados de Chile. Se discute si acaso ello no estaría vulnerando la Constitución Política de la República (2005), y las leyes al regular asuntos que por su naturaleza son materia de ley. En este debate, la referida asociación ha impulsado una agenda destinada a limitar estas facultades de los tribunales superiores, incluso a través de la presentación de una solicitud en que se pide a la misma Corte Suprema que deje sin efecto algunos auto acordados referidos a nombramientos, capacitación y calificación de los jueces y juezas (Flores Monardes, 2014).

Cabe preguntarse, entonces, si el auto acordado dictado por el Tercer Tribunal Ambiental podría ser objeto de cuestionamientos similares, toda vez que regula un procedimiento para llevar adelante el trámite de la consulta y sus efectos en sede ambiental, cuestión que debe ser regulada por la Ley. Habría que preguntarse, además, si el contenido de dicho auto acordado resulta coherente con la tramitación que se da a la consulta en los otros procedimientos que la contemplan, como el procedimiento de hacienda, el procedimiento de concesiones mineras, el recurso de amparo económico, antes revisados.

\subsection{Efectos de la sanción de clausura}

Este punto dice relación con la determinación de la "entrada en vigencia" de la sanción de clausura, es decir, desde cuándo produce efectos la sanción.

Para el Segundo Tribunal Ambiental, cuando se eleva en consulta una sanción de clausura y la misma es reclamada, la resolución sancionatoria es ejecutable desde la presentación del reclamo, siendo obligación del sujeto sancionado pedir en dicho acto o en un momento posterior, la suspensión de los efectos de la señalada resolución (Solicitud de medida provisional de clausura del sector de pozos de extracción de agua de Compañía Minera Maricunga, 2016) ${ }^{13}$.

\footnotetext{
${ }^{13}$ Resolución de fecha 14 de julio de 2016, que rechaza la solicitud de Medida Urgente y Transitoria (MUT) presentada por la SMA, consistente en la clausura parcial de un sector de los pozos de extrac- 
A su vez, sostiene que terminado el proceso de consulta la resolución sancionatoria es inmediatamente exigible "...por cuanto no se trataba de una sanción de multa sino de clausura de los pozos de extracción de agua, cuyo objetivo y bien jurídico protegido, era el medio ambiente..." (SCM Compañia Minera Maricunga / Superintendencia del Medio Ambiente [Res. Ex. N571, de 23 de junio 2016], 2017, cons. 26).

Para el Tercer Tribunal Ambiental, la situación es distinta dado que el trámite de la consulta procede antes de la notificación de la resolución sancionatoria al infractor, por lo que la sanción producirá efectos sólo desde su posterior notificación.

Por último, cabe tener presente que el Primer Tribunal Ambiental, al pronunciarse sobre la solicitud de la Superintendencia del Medio Ambiente de autorización de una medida urgente y transitoria de paralización del Proyecto Pascua-Lama (Ver procedimiento seguido en SMA con Compañía Minera Nevada SPA, 2018) - mientras se hacía ejecutable la sanción de clausura -, no se pronunció sobre este aspecto, sino que sostuvo que esta medida no era necesaria dado que el proyecto no generaba un daño grave e inminente al medio ambiente por encontrarse paralizado desde 2013. A su vez, la denegación de la medida se basó en que la solicitud carecía de objeto, puesto que ya existía una paralización ordenada judicialmente por la Corte de Apelaciones de Copiapó y confirmada por la Corte Suprema.

Para resolver el problema aquí planteado, se deben tener presentes las siguientes disposiciones de la Ley No 19.880, que se refieren a la entrada en vigencia de un acto administrativo. En primer lugar, sostiene:

Los actos administrativos gozan de una presunción de legalidad, de imperio y exigibilidad frente a sus destinatarios, desde su entrada en vigencia, autorizando su ejecución de oficio por la autoridad administrativa, salvo que mediare una orden de suspensión dispuesta por la autoridad administrativa dentro del procedimiento impugnatorio o por el juez, conociendo por la vía jurisdiccional. (Ley No 19.880, 2003, art. 3)

Por otra parte, señala que:

... Los actos de la Administración Pública sujetos al Derecho Administrativo causan inmediata ejecutoriedad, salvo en aquellos casos en que una disposición establezca lo contrario o necesiten aprobación o autorización superior.

Los decretos y resoluciones producirán efectos jurídicos desde su notificación o publicación, según sean de contenido individual o general. (Ley № 19.880, 2003, art. 51)

Cabe recordar, que la Ley Orgánica de la Superintendencia del Medio Ambiente establece una excepción a esta regla de ejecución inmediata, pero sólo res-

ción de agua del proyecto Maricunga, por la extensión temporal necesaria hasta que la sanción de clausura fuera ejecutable. Segundo Tribunal Ambiental, Rol S-41-2016, Solicitud de medida provisional de clausura del sector de pozos de extracción de agua de Compañía Minera Maricunga. 
pecto de las sanciones que constituyen multas, indicando que "Las resoluciones que impongan multas serán siempre reclamables y aquéllas no serán exigibles mientras no esté vencido el plazo para interponer la reclamación, o ésta no haya sido resuelta" (Ley $\mathrm{N}^{\circ} 20.417,2010$, art. segundo, art. 56, inc. 2). De lo anterior, se puede concluir que respecto de las otras sanciones rige la regla general, esto es, que las sanciones de clausura - y, también, de revocación de la Resolución de Calificación Ambiental - producen efectos desde su notificación al destinatario de la misma.

Sin embargo, habrá que preguntarse si el trámite procesal de la consulta constituye, en los términos de la Ley No19.880 (2003) una “...aprobación o autorización superior" (art. 51) que postergue la entrada en vigencia de la sanción hasta su cumplimiento. De acuerdo con Bermúdez Soto (2011) "no es correcto entender dicha circunstancia como una excepción a la ejecutoriedad, sino que se trata más bien de un acto administrativo que todavía no está perfecto, puesto que para nacer a la vida jurídica necesitará de la autorización o aprobación correspondiente" (p. 128).

Se puede concluir, que la posición del Segundo Tribunal Ambiental considera la consulta como una "autorización superior" que posterga los efectos de la sanción, ya que su entrada en vigencia corresponderá al momento en que termina el proceso de consulta, ya sea porque el tribunal se pronuncia al respecto o porque se interpone reclamación contra la resolución sancionatoria, y no se solicita por el sujeto sancionado la suspensión de los efectos de la sanción. Para el Tercer Tribunal, en cambio, el acto administrativo sancionatorio de la Superintendencia del Medio Ambiente requerirá para su perfeccionamiento del trámite de la consulta, por lo que la sanción sólo podrá ser notificada al infractor una vez que la consulta haya tenido lugar, lo que ocurrirá con anterioridad a dicho momento.

Sin perjuicio de las diferencias que aquí se relevan, los tribunales reconocen la "naturaleza cautelar" de la sanción de clausura y su "carácter correctivo de una situación fáctica que puede provocar una afectación al medio ambiente", por lo que si la sanción sólo fuera exigible - como ocurre con las multas - al resolver la reclamación judicial, podría perder eficacia y generar perjuicios al medio ambiente de difícil o imposible reversión. Lo anterior permite concluir que, en este punto, los tribunales ambientales - en el fondo - han sido consistentes y han entendido que la sanción de clausura produce efectos inmediatos, pero una vez resuelto el trámite de la consulta de acuerdo con el procedimiento aplicable, que como vimos, difiere para cada tribunal.

\subsection{Existencia de Interés público en el trámite de consulta}

La noción de interés público no es una cuestión fácil de dilucidar, menos si se trata de determinar si este existe o no para justificar la regulación de un determinado acto procesal, como la consulta. 
En Latinoamérica existe una cierta tendencia a identificar lo público con lo estatal, así se lo vincula preferentemente con la labor que realizan algunos órganos del Estado que desarrollan actividades donde se ve envuelto el patrimonio estatal (González Morales, 1997, pp. 22-23). A fines de los noventa, la discusión sobre el contenido de las denominadas acciones de interés público dio paso a una interesante reflexión acerca de "lo público" y el rol que este tipo de acciones tenían (y podrían tener) en el proceso de transición hacia la democracia en nuestro país (González Morales, 1997, p. 91). Su estudio, se vinculó a las llamadas acciones de interés colectivo y difuso que se definen como aquellas acciones que aluden a:

...intereses ubicados en la esfera de lo público, tradicionalmente imputables al Estado o a los órganos que los representan, y por extensión, a aquellos intereses que se refieren a las instituciones sociales básicas (v. gr. aquellos involucrados en la noción clásica de 'orden público', como la constitución de la familia, el resguardo de las fronteras, la represión de la delincuencia y muchos otros). (González Morales, 1997, p. 94)

Correa Fontecilla (2006) ha identificado ciertas características que integran el concepto de interés público. Así, en primer lugar menciona al bien común como contenido esencial, comprendiendo éste tres elementos:

el respeto a la persona en cuanto tal; el bienestar y desarrollo del grupo mismo; y la paz y la seguridad, correspondiendo al Estado defender y promover el bien común de la sociedad civil, de los ciudadanos y de las instituciones o grupos intermedios (p. 142)

Una segunda característica, consiste en que el interés público debe contribuir a la realización de la dignidad humana en la escala más amplia posible. Luego, el mismo autor señala como tercera característica, que se trata de un concepto que fortalece los principios democráticos y la convivencia pluralista (Correa Fontecilla, 2006, p. 142).

Continuando el análisis, Correa sostiene que el interés público también incluye los procesos de decisión que corresponden a las instituciones políticas y administrativas del Estado. Es decir, el interés público "estará representado por las intenciones elegidas y sancionadas por las autoridades mediante un procedimiento jurídico" (Correa Fontecilla, 2006, p. 144). Por otra parte, se trata de un concepto que representa los valores, principios, derechos y deberes consagrados en las Cartas Fundamentales, lo que a su vez permite sostener que su contenido es variable y dependerá de la elección de valores que cada sociedad adopte en una época determinada. Por último, señala que el interés público debe materializarse en un procedimiento administrativo, legislativo o jurisdiccional que pondrá término a la etapa de toma de decisión (Correa Fontecilla, 2006, p. 145). 
Por su parte, la jurisprudencia nacional entrega algunos elementos para la definición y comprensión de la noción de interés público. La revisión de algunos fallos de la Corte Suprema muestra, en primer lugar, la aplicación de esta noción en diferentes ámbitos. Por ejemplo, a propósito de la nulidad de contratos civiles, servidumbres eléctricas o asuntos de familia. En todo caso, se advierte un escaso desarrollo jurisprudencial de la noción de interés público, salvo alusiones tangenciales, pero sin un análisis profundo de su alcance o contenido utilizando dicha expresión como sinónimo de otras como interés colectivo o general. Por ejemplo, en un recurso de casación en la forma y en el fondo contra una sentencia dictada por una Corte de Apelaciones, en un caso sobre indemnización de servidumbres de obras hidroeléctricas, en un voto disidente se señala:

...es necesario tener en consideración que las llamadas servidumbres eléctricas constituyen un gravamen que puede afectar a un inmueble, cargas que presentan particularidades respecto de otras y que dejan de manifiesto el interés público que envuelven, puesto que no se trata de limitaciones impuestas a un predio en beneficio de otro predio, sino que de restricciones que se han establecido en beneficio del interés colectivo, del interés público, del interés general de la sociedad. (Empresa Eléctrica Pilmaiquén S.A. con Juan Fuchslocher, 2016, cons. 9 voto disidente)

Sin embargo, en otros fallos es posible encontrar algunos elementos que permiten delimitar los contornos de la noción de interés público. Ello se advierte, por ejemplo, en un caso de una servidumbre de alcantarillado sobre predios urbanos, allí la Corte Suprema rechazó un recurso de casación en el fondo señalando, entre otros argumentos, que este tipo de servidumbres constituyen gravámenes que se imponen a un predio en favor del interés público, que se encuentra establecido en leyes especiales y en la Constitución Política de la República, en virtud del cual se pueden imponer a la propiedad "...limitaciones y obligaciones que derivan de su función social, comprendiendo ésta cuando lo exijan los intereses generales de la nación y la utilidad pública y que se imponen a los inmuebles con el objeto de asegurar el funcionamiento de servicios públicos ..." (Luis Calderón Barahona con Empresa Sanitaria de Valparaíso ESVAL Ltda., 2016, cons. 1; véase también, Minera Pampa Fénix S.C.M. con Fisco de Chile, 2016, cons. 15). En este caso, la Corte Suprema vincula el interés público con la provisión de servicios básicos a la población (alcantarillado) actuando como un límite a la propiedad.

Por último, algunos fallos aluden también al interés público como límite, pero ahora en relación con la institución de la nulidad de oficio, dando sentido a la noción de interés público en contraposición del interés privado. En efecto, en un caso sobre la nulidad de un contrato por vicios de consentimiento, la Corte Suprema al casar de oficio sostiene que la facultad de los tribunales de anular de oficio una resolución judicial procede para la protección de las garantías constitucionales, entre ellas, el debido proceso. En ese sentido, dicha facultad se encuentra limitada por el interés 
público "...excluyendo de esa labor oficiosa, los actos dispuestos en interés particular de los litigantes...". (Luis Dante Orellana Ortúzar y otros con Celia Ortúzar y Lilian Orellana Ortúzar, 2012, cons. 9; véase además, Leiva Barrientos María Bernardita con Márquez Hernández María Elsa, 2014, cons. 10; Yusseff y Compañía Limitada con Manuel Medel Lepe, 2016, cons. 9).

A partir de lo analizado sobre el concepto e interpretaciones del contenido del interés público, nos debemos preguntar - para los efectos de este trabajo - acerca de cuáles son los valores y objetivos que persigue el Estado, mediante la aplicación de sanciones ambientales. En efecto, tal como se señaló con anterioridad, la consulta es una institución procesal que "vela por el resguardo de los intereses públicos o sociales en un caso seguido ante los tribunales". Cabe en todo caso recordar, que la consulta en materia ambiental, tiene un carácter sui generis, puesto que no se fundamenta en la revisión de sentencias de tribunales inferiores por los tribunales superiores, sino que busca ejercer un control previo, en sede judicial, respecto de una resolución administrativa que adopta un tipo específico de sanción ambiental. Sin perjuicio de lo anterior, no cabe duda que con la consulta de la sanción ambiental, se pretende resguardar el interés público envuelto en la aplicación de ciertas sanciones ambientales, estas son, la clausura y la revocación de la Resolución de Calificación Ambiental.

La característica que distingue a estas sanciones ambientales de las multas - y de la amonestación - (Ley $N^{\circ} 20.417,2010$, art. 38) ${ }^{14}$, dicen relación con su objetivo de impedir la continuación de la actividad económica que origina la infracción sancionada. Existe, por lo tanto, una posible afectación del derecho a desarrollar actividades económicas, consagrado en nuestra Constitución Política de la República (2005, art. 19, $\left.\mathrm{N}^{\circ} 21\right)$. No se deben minimizar las consecuencias extremadamente graves que genera la clausura de una instalación o la revocación de una Resolución de Calificación Ambiental. Estas incluyen no sólo una afectación patrimonial a los titulares de la actividad, sino que involucran también la pérdida de la fuente de trabajo de otras personas, y un posible perjuicio el desarrollo económico de la sociedad en general. La determinación de estas sanciones en particular, por lo tanto, debe reflejar una aplicación adecuada del principio de proporcionalidad en materia sancionatoria y constituye, sin dudas, un asunto de interés público.

Así, la Ley Orgánica de la Superintendencia del Medio Ambiente (art. 40, 2010) ha establecido la aplicación de ciertas circunstancias, para efectos de la determinación adecuada de la sanción ambiental, de manera de vincular la infracción a la respuesta sancionatoria precisa que le corresponda. De acuerdo con las Bases Metodológicas para la Aplicación de Sanciones Ambientales, elaboradas por la Superinten-

\footnotetext{
${ }^{14}$ Identifica las siguientes sanciones que puede imponer la Superintendenia de Medio Ambiente: amonestación por escrito; multa de una a diez mil unidades tributarias anuales; clausura temporal o definitiva; revocación de la Resolución de Calificación Ambiental.
} 
denia de Medio Ambiente [SMA] (2017), "La imposición de la revocación de la RCA o la clausura, en desmedro de una sanción pecuniaria, puede justificarse por fines disuasivos, por fines cautelares o por una combinación de ambos" (p. 84). Así, sostiene que se justificará por fines disuasivos, cuando las circunstancias de la comisión de la infracción dan cuenta de que una sanción pecuniaria no va a lograr ser un desincentivo suficiente para la comisión de infracciones futuras por parte del infractor. Se tomarán especialmente en cuenta aspectos como la magnitud del daño o riesgo causado al medio ambiente o la salud de las personas, la contumacia del infractor, la intencionalidad con la que ha actuado, la magnitud del beneficio económico obtenido, especialmente en los casos en los cuales este último excede el máximo legal de la multa, entre otros criterios (SMA, 2017, p. 84). Por otra parte, se justificará por fines cautelares cuando a través de estas sanciones:

... se busque resguardar al medio ambiente o la salud de las personas de un efecto que amenaza con extenderse en el tiempo, más allá de la fecha de la resolución sancionatoria. En la adopción de esta decisión se considerará especialmente el tipo y significancia del daño o riesgo, así como los antecedentes que hacen presumir que este continuará en el futuro y por cuánto tiempo. (SMA, 2017, p. 85)

Es decir, la autoridad deberá ponderar en la determinación de la sanción ambiental adecuada para un caso concreto, una serie de objetivos, valores y derechos que son parte de la función pública del Estado, estos son, los derechos al medio ambiente, a la salud de las personas, y también el derecho a desarrollar actividades económicas y el derecho de propiedad. Son estos los valores en juego, cuando hablamos del "interés público" involucrado en la determinación de sanciones ambientales como la clausura y la revocación de la licencia ambiental.

La pregunta es si dicho interés público justifica la institución de la consulta como trámite procesal, existiendo en la ley un recurso de reclamación para el afectado que garantiza una revisión judicial de la sanción aplicada por la Superintendencia del Medio Ambiente, por medio de tribunales especializados (Ley $\mathrm{N}^{\circ}$ 20.600, 2012, art. 17, no. 3) ${ }^{15}$. Es nuestra opinión que no existe en la actualidad una razón que permita concluir que este constituye un trámite necesario, y que su eventual eliminación sería consistente con la evolución que ha experimentado esta institución en los distintos procedimientos de nuestro ordenamiento jurídico donde se la ha contemplado. Que aún exista en sólo tres procedimientos no penales de carácter muy específico, como se ha revisado en estas páginas, es solo un resabio de una vieja y antigua legislación que en la actualidad parece haber perdido razón de ser. Ello podía enten-

\footnotetext{
${ }^{15}$ Establece que los Tribunales Ambientales serán competentes para conocer de las reclamaciones en contra de las resoluciones de la Superintendencia del Medio Ambiente, en conformidad con lo dispuesto en el artículo 56 de la Ley Orgánica de la Superintendencia del Medio Ambiente. Luego, el artículo 18 №3 señala que podrán interponer estas reclamaciones "las personas naturales o jurídicas directamente afectadas por la resolución de la SMA".
} 
derse en el marco del procedimiento de hacienda, cuya regulación data de principios del siglo pasado, pero no parece acorde a los tiempos haberla incluído en procedimientos regulados en los ochenta y noventa, y menos en el caso de la Ley Orgánica de la Superintendencia del Medio Ambiente publicada hace menos de 10 años.

Consideramos que el interés público involucrado en estos casos, se encuentra debidamente protegido en la medida que existe tanto un procedimiento administrativo sancionatorio, con todas las garantías que la ley entrega a los regulados, como un procedimiento jurisdiccional que podrá revisar la decisión administrativa. El trámite de la consulta no agrega, por lo tanto, ninguna protección mayor a la ya existente en la legislación aplicable. Por el contrario, como se ha visto en las secciones anteriores de este trabajo, simplemente parece agregar confusión y superposición en el ejercicio de las atribuciones contempladas en la nueva institucionalidad ambiental.

\section{Conclusiones}

El objetivo de este trabajo, fue revisar el fundamento y la evolución del trámite procesal de la consulta en nuestro ordenamiento jurídico, con el fin de analizar su reciente incorporación y aplicación respecto de las sanciones administrativas ambientales. La finalidad de este análisis, era determinar si tal trámite procesal se justificaba desde la perspectiva del interés público involucrado en la aplicación de sanciones ambientales.

Para ello, en primer lugar, se examinó la consulta como trámite procesal, su origen, objetivos y marco regulatorio actual, con el fin de ofrecer una panorámica del estado del arte en esta materia. En las últimas décadas, se observa una tendencia hacia la eliminación de la consulta como trámite obligatorio, tal como sucedió en materia penal y en los casos de nulidad y divorcio permaneciendo, sin embargo, intacta desde 1903 sólo en el procedimiento de hacienda e incorporándose décadas más tarde al procedimiento de concesión minera, en 1983 y al amparo económico, en 1990.

La Ley Orgánica de la Superintendencia del Medio Ambiente (2010), trae de vuelta esta institución para aquellos casos en que la autoridad ambiental decida aplicar ciertas sanciones administrativas (clausura y revocación de Resolución de Calificación Ambiental). Se pudo establecer que, desde la entrada en vigencia de las potestades sancionatorias de la Superintendencia del Medio Ambiente, en el año 2013, hasta la fecha (septiembre de 2019), nunca se ha adoptado la sanción de revocación de la Resolución de Calificación Ambiental y se ha impuesto la sanción de clausura sólo en ocho casos. De estos, cuatro casos fueron objeto de reclamación judicial por alguna de las partes en el procedimiento administrativo sancionatorio. 
Llama la atención que - pese a existir en estos casos reclamaciones judiciales de parte de los interesados - dos tribunales ambientales (Primero y Tercero) igualmente se pronunciaron sobre la consulta: en uno de ellos se confirmó la decisión de la Superintendencia del Medio Ambiente (Consulta de la Superintendencia del Medio Ambiente sobre Resolución Exenta $N^{\circ} 411$, de 5 de abril de 2018, 2018) y en el otro, en cambio, se anuló parcialmente ${ }^{16}$. A partir de lo analizado en este trabajo, creemos que, en estos casos, el objetivo de la consulta se desdibuja y pierde sentido y cabe preguntarse ¿por qué razón los tribunales ambientales conocen por esta vía de una decisión administrativa cuando las partes han ejercido su derecho a impugnarla?

Por su parte, respecto a los cuatro casos en que no se registra reclamación judicial, todos del Segundo Tribunal Ambiental, éste se pronuncia sobre la consulta, tal como lo exige la ley. En tres de ellos el tribunal confirma la sanción impuesta por la Superintendencia del Medio Ambiente, y sólo en uno de ellos la invalida. Es decir, de los ocho casos en que se ha aplicado la consulta como trámite procesal, sólo en uno de ellos se ha anulado la sanción ambiental impuesta por la autoridad administrativa.

Tal como lo hemos sostenido aquí, el trámite de la consulta no parece constituir una institución necesaria desde la perspectiva de la protección del interés público. Sólo se podría llegar a justificar esta institución, si se la considera como un trámite procesal basado en una lógica jerárquica de revisión de oficio de las decisiones de un órgano inferior por otro superior. Hemos visto que tal fundamento ha perdido valor para explicar la consulta al interior del Poder Judicial. Con mayor razón estimamos que no puede ser un argumento suficiente para entender la consulta cuando opera entre dos poderes independientes del Estado, esto es, cuando el Poder Judicial debe revisar una decisión de la Administración, como ocurre en el caso de las sanciones ambientales.

A todo lo anterior, se suma la existencia de una dispar interpretación de esta obligación legal por parte de los Tribunales Ambientales, lo que, a nuestro juicio, no hace sino acrecentar las dudas sobre su conveniencia, y generar un ambiente de incerteza jurídica a la hora de dar aplicación a este trámite procesal.

\section{Referencias Bibliográficas}

Acta de Sesión Extraordinaria № 2/2018. Modifica acuerdo contenido en Acta de Sesión Extraordinaria no 3/2013, en materia de consultas. Tercer Tribunal Ambiental, Valdivia, 18 de abril de 2018. Recuperado de https://bit.ly/3pxnFrH

\footnotetext{
${ }^{16}$ El caso es el Rol S-5-2018 del Primer Tribunal Ambiental. Sin perjuicio que, con posterioridad, esta resolución es a su vez anulada por la Corte Suprema, como se señaló con anterioridad.
} 
Acta de Sesión Extraordinaria $N^{\circ} 3 / 2013$. Sobre autorizaciones y consulta. Terecer Tribunal Ambiental, Valdivia, 9 de diciembre de 2013. Recuperado de https://bit.ly/3pAftXY

Agrícola Dos Hermanos Limitada con Ministros del Primer Tribunal Ambiental de Antofagasta, Rol No 26347-2018 (Corte Suprema 14 de marzo de 2019). Recuperado de https://westlawchile.cl id: CL/JUR/1303/2019

Agrícola Dos Hermanos Limitada y Otros con Superintendencia del Medio Ambiente, Rol N R-6-2018 (Primer Tribunal Ambiental 5 de febrero de 2018). Recuperado de https://bit.ly/3pCvVXD

Bermúdez Soto, J. (2011). Derecho administrativo general (2a ed.). Santiago: Legal Publishing.

Bordalí Salamanca, A., Cortéz Matcovich, G. y Palomo Vélez, D. (2016). Proceso civil: Los recursos y otros medios de impugnación. Santiago: Thomson Reuters.

Cárcamo Righetti, A. (1 abril, 2015). Una revisión crítica a la interpretación judicial que ha desnaturalizado la acción de amparo económico: ¿un camino sin retorno? Primera parte. Diario constitucional. Recuperado de https://bit.ly/3grsek4

Carocca Pérez, A. (2000). Recursos en el Nuevo Sistema Procesal Penal. En A. Carocca Pérez, M. Duce Julio, C. Riego Ramírez, A. Baytelman Aronowsky, J. E. Vargas Viancos (Autores), Nuevo proceso penal: incluye texto completo del nuevo código procesal penal (pp. 297-331). Santiago: Jurídica ConoSur.

Carocca Pérez, A. (2003). Manual de derecho procesal: los procesos declarativos. Santiago: Lexis Nexis, Santiago.

Chaigneau del Campo, A. (2002) Tramitación en las Cortes de Apelaciones (5a ed.). Santiago: Jurídica de Chile.

Compañía Minera Nevada Spa con Superintendencia del Medio Ambiente, Rol $N^{\circ} \mathrm{R}-$ 5-2018 (Primer Tribunal Ambiental 3 de febrero de 2018). Recuperado de https://bit.ly/3mRSK7O

Constitución Política de la República de Chile. Diario Oficial de la República de Chile, Santiago, Chile, 22 de septiembre de 2005. Recuperado de http://bcn.cl/1uva9

Consulta de la Superintendencia del Medio Ambiente sobre Res. Ex. N 234, de 17 de Marzo de 2016, Rol N C-6-2016 (Segundo Tribunal Ambiental 13 de julio de 2016). Recuperado de https://bit.ly/2L6hl6o

Consulta de la Superintendencia del Medio Ambiente sobre Res. Ex. SMA No 363 de 04 de mayo de 2015, Rol N ${ }^{\circ}$ C-5-2015 (Segundo Tribunal Ambiental 8 de septiembre de 2015). Recuperado de https://bit.ly/3hqnV8Z 
Consulta de la Superintendencia del Medio Ambiente sobre Res. Ex. N ${ }^{\circ} 432$, de 01 de junio de 2015, Rol N C-4-2015 (Segundo Tribunal Ambiental 8 de septiembre de 2015). Recuperado de https://bit.ly/2WXv5Ip

Consulta de la Superintendencia del Medio Ambiente sobre Res. Ex. SMA N ${ }^{\circ}$ 591, de 17 de junio de 2013, Rol N C-1-2013 (Segundo Tribunal Ambiental 29 de julio de 2013). Recuperado de https://bit.ly/3pxswtc

Consulta de la Superintendencia del Medio Ambiente sobre Res. Ex. SMA N ${ }^{\circ} 601$, de 19 de junio de 2013. Rol N C-2-2013, (Segundo Tribunal Ambiental 29 de julio de 2013). Recuperado de https://bit.ly/2MghoCz

Consulta de la Superintendencia del Medio Ambiente sobre Res. Ex. SMA N 695 de fecha 24 de noviembre de 2014, Rol N C-3-2014 (Segundo Tribunal Ambiental 29 de enero de 2015). Recuperado de https://bit.ly/3rwZCeh

Consulta de la Superintendencia del Medio Ambiente sobre Resolución Exenta $\mathrm{N}^{\circ}$ 411, de 5 de abril de 2018, Rol № C-1-2018 (Tercer Tribunal Ambiental 9 de mayo de 2018). Recuperado de https://bit.ly/3rxSFcZ

Correa Fontecilla, J. (2006). Algunas consideraciones sobre el interés público en la política y el derecho. Revista española de control externo, 8 (24), 135-161. Recuperado de https://bit.ly/3704yT0

Couture Etcheverry, E. (2016). Fundamentos de derecho procesal civil. Montevideo: Euros Editores.

Duce Julio, M. y Riego Ramírez, C. (2007). Proceso penal. Santigo: Jurídica de Chile.

Empresa Eléctrica Pilmaiquén S.A. con Juan Fuchslocher, Rol N 1559-2015 (Corte Suprema 10 de noviembre de 2016). Recuperado https://westlawchile.cl id: CL/JUR/8158/2016

Flores Monardes, Á. (17 diciembre, 2014). Solicta [sic] al Tribunal Pleno que derogue la normativa contenida en autos acordados que indica por contravenir la Constitución Política de la República y la Ley. Recuperado de https://bit.ly/34U4ZdO

González Morales, F. (1997). Relatoría general proyecto sobre acciones de interés público. Cuaderno de análisis Jurídico, (7), 15-48.

Historia de la Ley $N^{\circ}$ 20.417. Crea el ministerio, el servicio de evaluación ambiental y la superintendencia del medio ambiente. Biblioteca del Congreso Nacional, 11 de mayo de 2018. Recuperado de http://s.bcn.cl/20qah

Historia de la Ley $N^{\circ} 20.600$. Crea los tribunales ambientales. Biblioteca del Congreso Nacional, 03 de mayo de 2018. Recuperado de http://s.bcn.cl/22yfe 
Horvitz Lennon, M. I. y López Masle, J. (2014). Derecho procesal penal Nol. 2). Santiago: Jurídica de Chile.

Huidobro Salas, R. (2010). Orden Público Económico y Regulación (Notas sobre la regulación de la actividad comercial por vía electrónica). Revista de Derecho Público, (73), 243- 260, doi: 10.5354/0719-5249.2014.35669

Leiva Barrientos María Bernardita con Márquez Hernández María Elsa, Rol N 77982014 (Corte Suprema 27 de noviembre de 2014). Recuperado de https://westlawchile.cl id: CL/JUR/9028/2014

Letelier Loyola, E. (2013). El derecho fundamental al recurso en el proceso penal. BarceIona: Atelier.

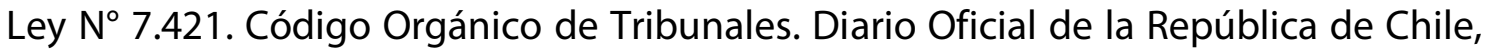
Santiago, Chile, 09 de julio de 1943. Recuperado de http://bcn.cl/2fa3i

Ley $N^{\circ}$ 1.552. Código de procedimiento civil. Diario Oficial de la República de Chile, Santiago, Chile, 30 de agosto de 1902. Recuperado de http://bcn.cl/1uw3q

Ley N 18.097. Ley Orgánica Constitucional sobre Concesiones Mineras. Diario Oficial de la República de Chile, Santiago, Chile, 21 de enero de 1982. Recuperado de http://bcn.cl/2j4vv

Ley N ${ }^{\circ}$ 18.248. Código de Minería. Diario Oficial de la República de Chile, Santiago, Chile, 14 de octubre de 1983. Recuperado de http://bcn.cl/2fcpf

Ley $N^{\circ}$ 18.971. Establece recurso especial que indica. Diario Oficial de la República de Chile, Santiago, Chile, 10 de marzo de 1990. Recuperado de http://bcn.cl/2k84f

Ley $\mathrm{N}^{\circ} 19.880$. Establece bases de los procedimientos administrativos que rigen los actos de los organos de la administracion del Estado. Diario Oficial de la República de Chile, Santiago, Chile, 29 de mayo de 2003. Recuperado de http://bcn.cl/2f82e

Ley $N^{\circ}$ 19.968. Crea los Tribunales de familia. Diario Oficial de la República de Chile, Santiago, Chile, 30 de agosto de 2004. Recuperado de http://bcn.cl/2f6gg

Ley N 19.947. Establece Nueva Ley de Matrimonio Civil. Diario Oficial de la República de Chile, Santiago, Chile, 17 de mayo de 2004. Recuperado de http://bcn.cl/2i57i

Ley $\mathrm{N}^{\circ}$ 20.286. Introduce modificaciones orgánicas y procedimentales a la Ley $\mathrm{N}^{\circ}$ 19.968, que crea los Tribunales de familia. Diario Oficial de la República de Chile, Santiago, 15 de septiembre de 2008. Recuperado de http://bcn.cl/2f92s

Ley $N^{\circ}$ 20.417. Crea el Ministerio, el Servicio de Evaluación ambiental y la Superintendencia del Medio ambiente. Diario Oficial de la República de Chile, Santiago, Chile, 26 de enero de 2010. Recuperado de http://bcn.cl/2m768 
Ley N² 20.600. Crea los Tribunales ambientales. Diario Oficial de la República de Chile, Santiago, Chile, 28 de junio de 2012. Recuperado de http://bcn.cl/1v6nd

Luis Calderón Barahona con Empresa Sanitaria de Valparaíso ESVAL Ltda., Rol № $822-$ 2016 (Corte Suprema 7 de diciembre de 2016). Recuperado https://westlawchile.cl id: CL/JUR/8100/2016

Luis Dante Orellana Ortúzar y otros con Celia Ortúzar y Lilian Orellana Ortúzar, Rol N ${ }^{\circ}$ 2718-2011 (Corte Suprema 14 de marzo de 2012). Recuperado de https://westlawchile.cl id: CL/JUR/594/2012

Minera Pampa Fénix S.C.M. con Fisco de Chile, Rol N 12886-2015 (Corte Suprema 5 de septiembre de 2016). Recuperado de https://westlawchile.cl id: $\mathrm{CL} / J U R / 6314 / 2016$

Mosquera Ruíz, M. y Maturana Miquel, C. (2010). Los recursos procesales. Santiago: Jurídica de Chile.

Orellana Torres, F. (2006). Medios de impugnación y recursos procesales en la ejecución de condenas no dinerarias. lus et praxis, 12(2). doi: 10.4067/s071800122006000200007

Palomo Vélez, D. I. (2010). Apelación, doble instancia y proceso civil oral: a propósito de la reforma en trámite. Estudios constitucionales, 8(2), 465-524. doi: 10.4067/S071852002010000200014

Piedrabuena Richard, G. (1999). El recurso de apelación y la consulta. Santiago: Jurídica de Chile.

Proyecto de Ley. Modifica diversos cuerpos legales, en lo relativo al trámite de consulta al tribunal superior. Senado de la República de Chile, Boletín 5629-07, Valparaíso, 19 de diciembre de 2007. Recuperado de https://bit.ly/2W2SOqs

Resolución Exenta № 72. Resuelve procedimiento administrativo sancionatorio, Rol A-002-2013, seguido en contra de Compañía Minera Nevada SpA. 17 de enero de 2018. Superintendencia del Medio Ambiente, Santiago, 17 de enero de 2018. Recuperado de https://bit.ly/2LpZtss

Resolución Exenta № 234. Resuelve procedimiento administrativo sancionatorio, Rol D-014-2015, seguido en contra de Sociedad Contractual Minera Comparía Minera Maricunga. Superintendencia del Medio Ambiente, Santiago, 17 de marzo de 2016. Recuperado de https://bit.ly/3rVAOIn

Resolución Exenta № 363. Resuelve procedimiento administrativo sancionatorio, Rol F-054-2014, seguido en contra de Anglo American Sur S.A. Superintendencia del Medio Ambiente, Santiago, 04 de mayo de 2015. Recuperado de https://bit.ly/2L3UyOd 
Resolución Exenta № 432. Resuelve procedimiento administrativo sancionatorio, Rol F-012-2014, seguido en contra de minera Española Chile Limitada. Superintendencia del Medio Ambiente, Santiago, 1 de junio de 2015. Recuperado de https://bit.ly/391 bkFO

Resolución Exenta $N^{\circ}$ 591. Resuelve procedimiento administrativo sancionatorio Rol D-002-2013 contra Al Hamo Import Export Ltda. Superintendencia del Medio Ambiente, Santiago, 17 de junio de 2013. Recuperado de https://bit.ly/3pPPICY

Resolución Exenta $N^{\circ} 601$. Resuelve procedimiento administrativo sancionatorio Rol F-004-2013 contra Granja Marina Tornagaleones S.A. Superintendencia del Medio Ambiente, Santiago, 19 de junio de 2013. Recuperado de https://bit.ly/3rQDJ9Y

Resolución Exenta $N^{\circ}$ 695. Resuelve procedimiento administrativo sancionatorio, Rol D-014-2013, seguido en contra de Tecnorec S.A. Superintendencia del Medio Ambiente, Santiago, 24 de noviembre de 2014. Recuperado de https://bit.ly/3nqqERz

Resolución Exenta No 571. Resuelve presentación que indica. Superintendencia del Medio Ambiente, Santiago, 23 de junio de 2016. Recuperado de https://bit.ly/2XdgjgT

Resolución Exenta № 411. Resuelve procedimiento administrativo sancionatorio, Rol F-017-2016, seguido en contra de Agrícola y Frutícola Veneto Ltda. Superintendencia del Medio Ambiente, Santiago, 5 de abril de 2018. Recuperado de https://bit.ly/3ng3fSI

Resolución Exenta No 561. Comunica resultado de trámite de consulta de la sanción por la Res. Ex. № 411, de 5 de abril de 2018. Superintendencia del Medio Ambiente, Santiago, 15 de mayo de 2018. Recuperado de https://bit.ly/3hMfHbt

Robles Pantoja Alberto/Superintendencia del Medio Ambiente (Res. Ex. N ${ }^{\circ}$ 695, de 24 de noviembre de 2014), Rol N R-58-2015 (Segundo Tribunal Ambiental 15 de octubre de 2015). Recuperado de https://bit.ly/3mOS7fi

SCM Compañia Minera Maricunga / Superintendencia del Medio Ambiente (Res. Ex. $N^{\circ}$ 571, de 23 de junio 2016), Rol N R-118-2016 (Segundo Tribunal Ambiental 31 de agosto de 2017), Recuperado de https://bit.ly/3pzVCbj

SMA con Compañía Minera Nevada SPA, Rol N S-3-2018 (Primer Tribunal Ambiental 08 de febrero de 2018). Recuperado de https://bit.ly/3aQg6rZ

Sociedad Contractual Minera Compañía Minera Maricunga con Superintendencia del Medio Ambiente, Rol N ${ }^{\circ}$ 42004-2017 (Corte Suprema 9 de octubre de 2018). Recuperado de https://westlawchile.cl id:CL/JUR/5706/2018 
Solicitud de medida provisional de clausura del sector de pozos de extraccion de agua de Compañia Minera Maricunga, Rol N S-41-2016 (Segundo Tribunal Ambiental 14 de julio 2016). Recuperado de https://bit.ly/3os29op

Superintendencia del Medio Ambiente. (2017). Bases metodológicas para la determinación de sanciones ambientales [PDF]. Recuperado de https://bit.ly/3nfFmuv

Superintendencia del Medio Ambiente con Compañía Minera Nevada Spa, Rol N S-52018 (Primer Tribunal Ambiental 12 de octubre de 2018) Recuperado de https://bit.ly/3hkTAIY

Superintendencia del Medio Ambiente con Compañía Minera Nevada Spa, Rol No S-52018 (Resolución) (Primer Tribunal Ambiental 22 de marzo de 2018). Recuperado de https://bit.ly/3psfPjg

Superintendencia del Medio Ambiente con Compañía Minera Nevada Spa, Rol № S-52018 (Resolución) (Primer Tribunal Ambiental 9 de abril de 2019). Recuperado de https://bit.ly/3aLsCcd

Yusseff y Compañía Limitada con Manuel Medel Lepe, Rol № 40667-2016. (Corte Suprema 15 de diciembre de 2016) Recuperado de https://westlawchile.cl id: CL/JUR/8315/2016

\section{Para citar este artículo bajo Norma APA 6a ed. \\ Hervé Espejo, D. y Vargas Pavez, M. (2021). La consulta de \\ la sanción ambiental: un trámite procesal innecesario. \\ Revista de Derecho (Coquimbo. En línea), 28, e3769. \\ https://doi.org/10.22199/issn.0718-9753-2021-0003}

Copyright del articulo: @2021 Dominique Hervé y Macarena Vargas 